\title{
A Study of Silver Halide Fibers Using Fiber Evanescent Wave Spectroscopy to Assess the Potential for In-vivo Diagnosis of Malignant Cervical Tissue
}

\author{
By \\ Patrick Assouad \\ A thesis submitted to the \\ Faculty of Graduate and Postdoctoral Affairs \\ in partial fulfillment of the requirements for the degree of \\ Master of Science \\ Department of Physics \\ Ottawa-Carleton Institute for Physics \\ Carleton University
}

(C) Patrick Assouad, Dec. 2010 


$\begin{array}{ll}\begin{array}{l}\text { Library and Archives } \\ \text { Canada }\end{array} & \begin{array}{l}\text { Bibliothèque et } \\ \text { Archives Canada }\end{array} \\ \begin{array}{l}\text { Published Heritage } \\ \text { Branch }\end{array} & \begin{array}{l}\text { Direction du } \\ \text { Patrimoine de l'édition }\end{array} \\ \begin{array}{l}\text { 395 Wellington Street } \\ \text { Ottawa ON K1A ON4 } \\ \text { Canada }\end{array} & \begin{array}{l}\text { 395, rue Wellington } \\ \text { Ottawa ON K1A ON4 } \\ \text { Canada }\end{array}\end{array}$

Your file Votre référence

ISBN: 978-0-494-79596-5

Our file Notre reférence

ISBN: 978-0-494-79596-5

NOTICE:

The author has granted a nonexclusive license allowing Library and Archives Canada to reproduce, publish, archive, preserve, conserve, communicate to the public by telecommunication or on the Internet, loan, distribute and sell theses worldwide, for commercial or noncommercial purposes, in microform, paper, electronic and/or any other formats.

The author retains copyright ownership and moral rights in this thesis. Neither the thesis nor substantial extracts from it may be printed or otherwise reproduced without the author's permission.

\begin{abstract}
AVIS:
L'auteur a accordé une licence non exclusive permettant à la Bibliothèque et Archives Canada de reproduire, publier, archiver, sauvegarder, conserver, transmettre au public par télécommunication ou par l'Internet, prêter, distribuer et vendre des thèses partout dans le monde, à des fins commerciales ou autres, sur support microforme, papier, électronique et/ou autres formats.
\end{abstract}

L'auteur conserve la propriété du droit d'auteur et des droits moraux qui protège cette thèse. $\mathrm{Ni}$ la thèse ni des extraits substantiels de celle-ci ne doivent être imprimés ou autrement reproduits sans son autorisation.
In compliance with the Canadian Privacy Act some supporting forms may have been removed from this thesis.

While these forms may be included in the document page count, their removal does not represent any loss of content from the thesis.
Conformément à la loi canadienne sur la protection de la vie privée, quelques formulaires secondaires ont été enlevés de cette thèse.

Bien que ces formulaires aient inclus dans la pagination, il n'y aura aucun contenu manquant. 


\begin{abstract}
An in-vivo technique providing real-time automated diagnosis would be an ideal alternative to Pap smears in many parts of the world. Mid-infrared spectrometry has this potential but to date has only been investigated for cervical applications using Fourier Transform Infrared (FTIR) spectrometry on ex-vivo samples. This study aims to determine if Fiber Evanescent Wave Spectroscopy (FEWS) can provide the same diagnosis value as FTIR spectroscopy for cervical cancer with the aim of application in an in-vivo environment. Twenty-three cervical tissue samples were used to perfect the FEWS methodology and provide spectral readings from both the FEWS and transmission FTIR approach. Of the samples showing valid spectra, only one was diagnosed differently by both techniques. The cause was however attributed to sample preparation difficulties rather than spectral information content. It is proposed that these results provide a FEWS proof-of-concept as well as sufficient evidence to support further development.
\end{abstract}




\section{ACKNOWLEDGEMENTS}

I would like to thank Dr. John Armitage and Dr. Patrick Wong for their continual support and encouragements throughout the project. Dr. Patrick Wong invested significant amount of effort to share his expertise in the spectrometry field as well as contributed important hardware, samples, as well as analysis time to this project. I am also greatly indebted to Dr. John Armitage who accepted to supervise this project and made his laboratory available as well as providing the necessary support to renovate and upgrade the infrastructure to allow the setup for the experimentation. I would also like to thank Dr. Paul Johns who first opened his door and took the time to find the mechanism through which this project could be undertaken at Carleton even though it did not fall in the traditional medical physics themes. Finally, I would like to extend my gratitude to the whole Department of Physics at Carleton, including the administrative staff (a special thanks to Eva Lacelle) for having been patient with me and the numerous delays that extended the duration of this project. 


\section{TABLE OF CONTENTS}

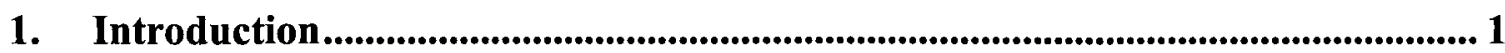

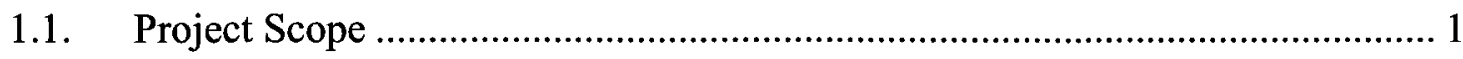

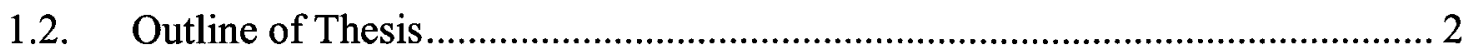

2. Mid-Infrared Spectrometry ....................................................................................................... 5

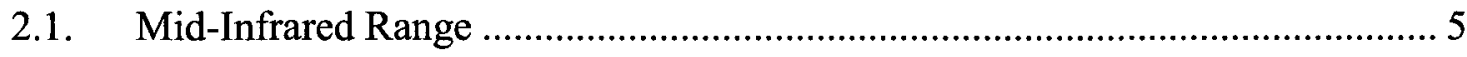

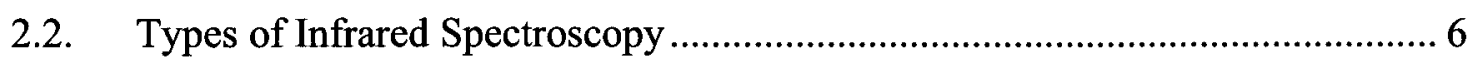

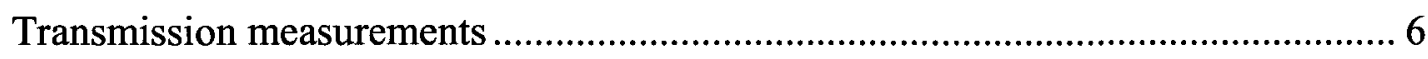

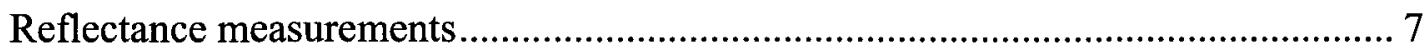

Attenuated Total Reflectance (ATR) measurements .................................................. 8

2.3. Fourier Transform Infrared Spectrometry ................................................ 9

2.4. Principles of Fiber-Evanescent-Wave Spectroscopy (FEWS).......................... 15

3. Optical Fibers for Mid-Infrared Transmission................................................................ 20

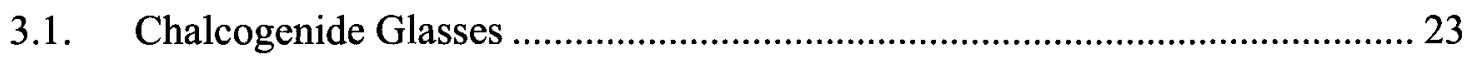

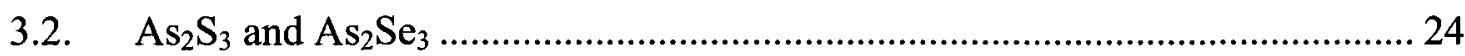

3.3. Ga-La-Na and Other Non-toxic Sulphides .................................................. 25

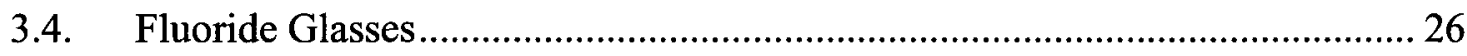

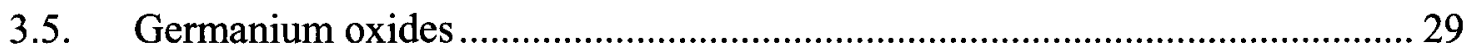

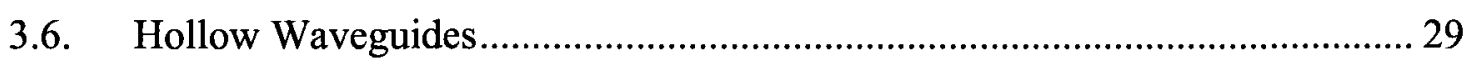

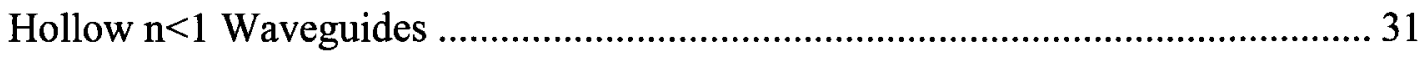

3.7. Polycrystalline Fibers............................................................................. 32

4. Mid-Infrared Tissue Response................................................................................................... 37

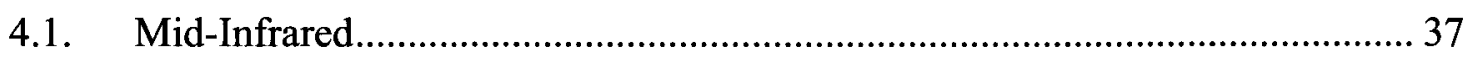

4.2. Review of Research on the use of FTIR for the Detection of Malignant Cells 39 
4.3. A Note on Sample Preparation ............................................................... 44

4.4. FTIR-FEWS Studies on Biosample Analysis ......................................... 47

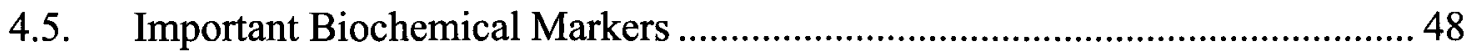

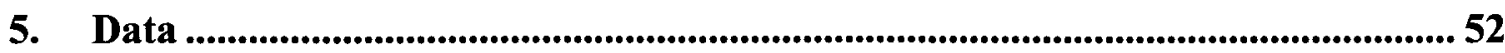

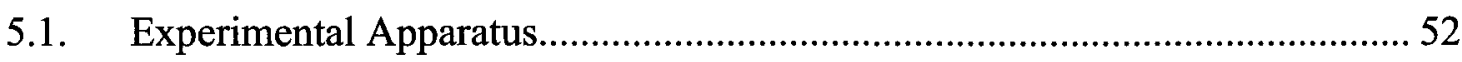

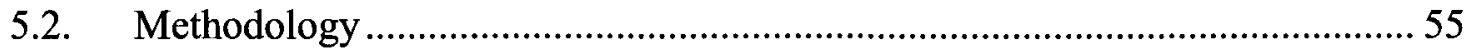

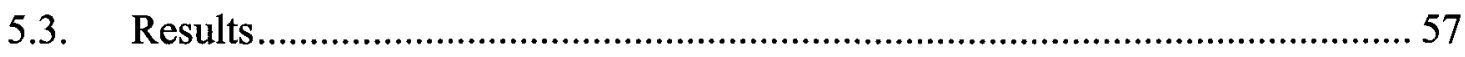

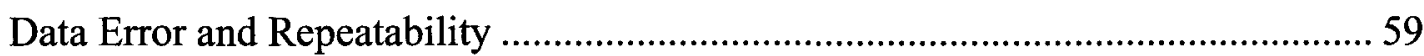

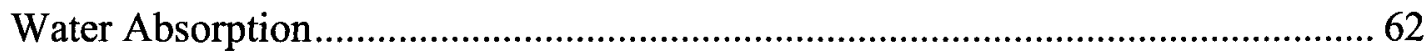

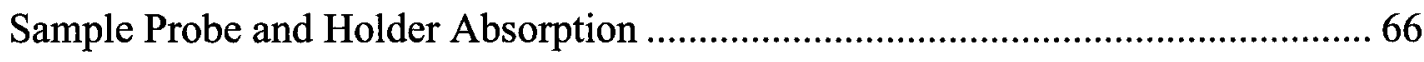

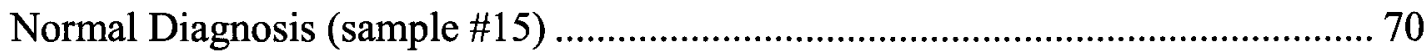

Abnormal Diagnosis (sample \#19) ............................................................ 72

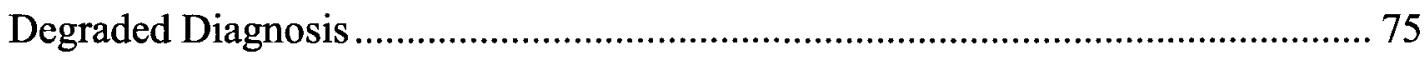

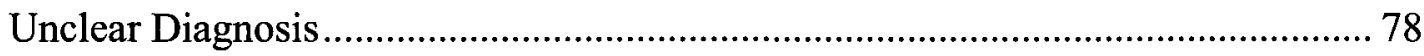

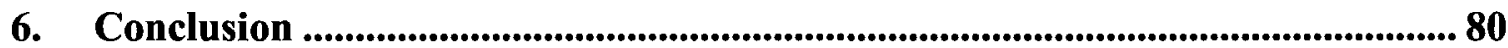

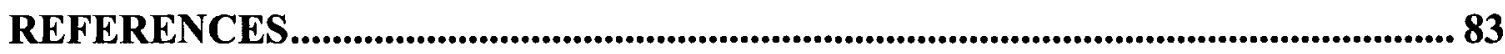




\section{LIST OF TABLES}

Table 1. Main characteristics of IR fiber classes. ................................................. 19

Table 2. Classification of infrared fibers. ............................................................ 22

Table 3. Physical and optical properties of infrared fibers compared to silica fibers...... 22

Table 4. Example refractive indices for various chalcogenide compositions................. 24

Table 5. As-S-Se family studied by Sundaram et al. ................................................ 25

Table 6. Main contributors to the spectral changes observed....................................... 49

Table 7. Classification results: shaded blocks indicate degraded spectra..................... 58 


\section{LIST OF FIGURES}

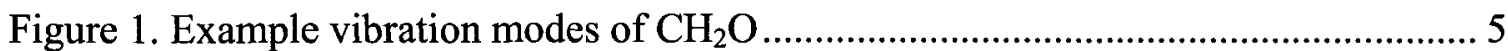

Figure 2. Different regimes for infrared spectrometry................................................. 7

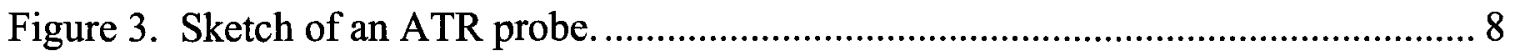

Figure 4. Basic design of a Fourier transform infrared spectrometer............................... 11

Figure 5. Interferogram showing peak intensity at zero path difference .......................... 12

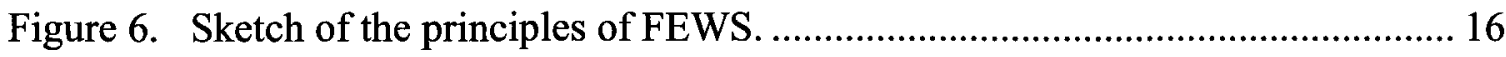

Figure 7. Attenuation curve for fluoride glass fibers reported by IR Photonics............... 27

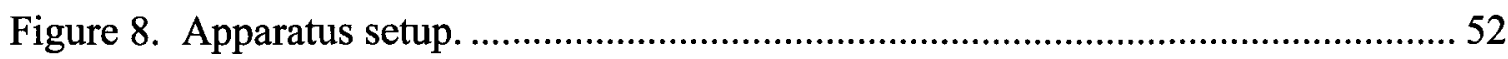

Figure 9. a) silicon sample slide holder; b) fiber probe............................................... 53

Figure 10. Optical path traversed through the fiber-coupler assembly............................. 54

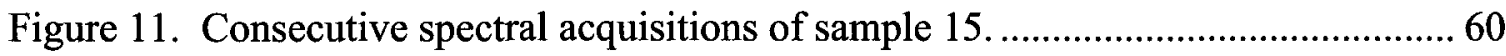

Figure 12, Spectral absorption variations over long time scale of sample 16................61

Figure 13, Absorption of pure water using FEWS methodology..................................... 63

Figure 14. Absorption spectra of a sample when still wet and after drying. ....................64

Figure 15. Emission spectrum of the spectrometer heat source.......................................... 66

Figure 16. Transmission of silver halide fiber and coupler assembly. .............................68

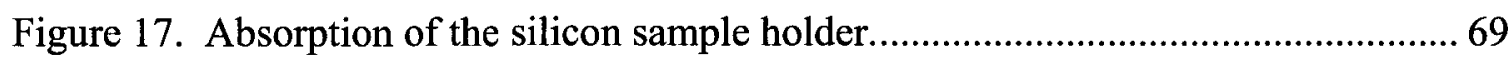

Figure 18. Absorption spectra of a normal tissue sample................................................ 70

Figure 19. Absorption spectra an abnormal tissue sample. .......................................... 72

Figure 20. FEWS absorption spectra of a normal and abnormal sample........................ 73

Figure 21. Absorption spectra of degraded tissue.......................................................... 75

Figure 22. A comparison of a degraded and an abnormal sample.................................. 76

Figure 23. Absorption spectra of a sample showing unclear results................................. 78 
All samples used in this study were collected by Dr Patrick Wong, University of Ottawa, and consent was given for their use in studies of malignant cervical cancer.

Though not funded by the Tri-Councils ( NSERC, SSHERC and MRC), this research did follow guidelines published on the government website:

www.pre.ethics.gc.ca/eng/policy-politique/initiatives/tcps2-eptc2/Default/ 


\section{Introduction}

\subsection{Project Scope}

There is a considerable need for an effective alternative to Pap smears for the screening of cervical cancer in most parts of the world. Pap smears have been the gold standard in developed countries and have proven crucial in the fight against cervical cancer. Screening programs in these countries have been well developed and shown to be the most important tool in fighting this type of cancer. Nonetheless, even though highly successful, Pap smears still suffer from an unusually high rate of false negatives that can range from $15-40 \%$ [1]. In addition, Pap smears require a high level of training and experience on the part of the pathologists performing the analysis. This skilled work force is seriously lacking in many parts of the world. An ideal alternative should provide an efficient, fast, and still inexpensive procedure for diagnosis.

About two decades ago, studies involving the use of mid-infrared spectrometry as a means of distinguishing malignant cells from healthy ones were undertaken. Since then, this application has been subject to steadily increasing interest given encouraging results. Studies pertaining to cervical cancer in particular have all been performed using traditional spectrometer setups. Although this approach has been promising, its introduction into a clinical setting has been and will always be hampered by the need for biopsies and sample preparation. An in-vivo assessment of tissue health would prove a significant step forward and raise interest from the clinical perspective. 
The work undertaken herein addresses this need. A novel technique termed Fiber Evanescent Wave Spectroscopy (FEWS) has recently undergone important developments due to advancement in mid-infrared fibers and is here applied and developed for cervical cancer diagnosis. Tissue absorption spectra have traditionally been acquired through Fourier Transform Infrared (FTIR) spectrometry in which biopsy samples are placed on slides transparent in the spectral range of interest. FEWS has the potential to acquire similar data without the need for tissue extraction by coupling an optical fiber to the spectrometer and transmitting the infrared radiation directly the tissue investigated where a non-invasively absorption reading is acquired. Within the scope of this project, a FEWS lab setup is constructed at Carleton University and cervical samples are used to assess the feasibility of applying this technique relative to the traditional FTIR spectrometry approach. A set of classification parameters based on previous published results and discussed below is used to derive the diagnosis. Emphasis is placed, not on validating this classification scheme, but on confirming that absorption spectra acquired through the FEWS methodology yields similar diagnosis classification as the traditional FTIR methodology.

\subsection{Outline of Thesis}

This report is divided into four main body chapters. In chapter 2 , the theoretical background for the use of mid-infrared radiation as a diagnostic tool for tissue health is briefly reviewed. The different types of spectrometric techniques possible for measuring 
tissue absorption at these wavelengths are also reviewed. More specifically, Fourier spectrometry in both its transmission and Attenuated Total Reflection (ATR) modes is presented as it is the standard technique used in the mid-infrared. Finally, an introduction is given to FEWS as it promises to allow application of traditional techniques in new environments such as in-vivo diagnostics.

Chapter 3 reviews mid-infrared optical fiber technologies that have been developed over the past few decades. FEWS relies heavily on efficient broad transmission of midinfrared radiation with fairly weak signal intensity. In the past, this has proven to be the major showstopper for the development on any mid-infrared fiber based spectroscopic tool since most fibers either had poor transmission or only transmitted in a narrow band which, however useful for laser applications, disallowed broad band applications such as spectrometry.

Chapter 4 first reviews the basic mid-infrared response of tissue in terms of the absorptions of the different bonds typically found in cells. The development of midinfrared spectrometry as a tool for detecting malignant transformation in cells is also reviewed. Nearly all of this work has been done using the traditional transmission approach in Fourier spectrometry. Only a few studies have attempted a FEWS approach and these are also presented. As a result of this work, identification of a few key spectral changes, or biomarkers, have been associated with dysplastic and malignant transformation and are summarized. 
Finally chapter 5 presents the methodology and results achieved within the scope of this project. Although results are given for all the samples processed, only one sample in each classified category is shown in detail to exemplify readings for each group. Conclusions and future outlook are drawn from these results. 


\section{Mid-Infrared Spectrometry}

\subsection{Mid-Infrared Range}

The mid-infrared (MIR) emissions and absorptions of molecules, spanning from $2 \mu \mathrm{m}$ to $30 \mu \mathrm{m}$ (or $350 \mathrm{~cm}^{-1}$ to $5000 \mathrm{~cm}^{-1}$ ), are indicative of dipole moment changes induced by their vibrations. Not all possible vibrations within a molecule will result in an absorption band in the infrared region. To be infrared active the vibration must result in a change of dipole moment during the vibration. This means that for symmetric diatomic molecules such as hydrogen $\left(\mathrm{H}_{2}\right)$, nitrogen $\left(\mathrm{N}_{2}\right)$ and oxygen $\left(\mathrm{O}_{2}\right)$, no infrared absorption is observed. Asymmetry as found in the very complex organic molecules making up cell structures is required for a dipole moment change. Another possibility is an induced dipole moment change within a symmetric molecule which has no permanent dipole moment. Figure 1 illustrates various vibration stretch and bending modes of a $\mathrm{CH}_{2} \mathrm{O}$ molecule which can lead to emission in the mid-infrared [2].

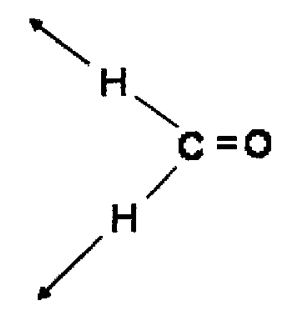

Symmetric $\mathrm{CH}$ stretch

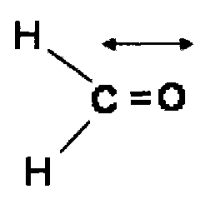

Symmetric CO stretch

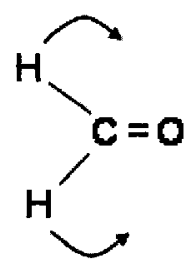

$\mathrm{CH}_{2}$ bend

Figure 1. Example vibration modes of $\mathrm{CH}_{2} \mathrm{O}$ 
The fact that there are many different vibrations within every molecule implies that the infrared spectrum of a compound usually holds a lot of information about the different modes of vibration and can serve to identify the molecule very accurately given good reference spectral databases.

\subsection{Types of Infrared Spectroscopy}

Routine measurement modes for MIR absorption spectroscopy are transmission, reflectance and attenuated total reflectance (ATR). The following briefly summarizes each of the regimes in order to put in-vivo measurements into perspective.

\section{Transmission measurements}

Transmission measurements are the traditional approach used in infrared spectrometry. Light from a broad-band light source, such as a heat source, is passed through the sample (see figure 2). The transmitted spectrum carries absorption information of the sample when compared to the known incident spectrum. Scattering effects can be generally neglected given the heavy absorption of infrared energy in this range by biological tissue. As well, samples in this mode require significant preparation as they should be thin and placed on an infrared transparent slide or diluted in a solution transparent to infrared light. This significantly limits potential for quasi-real-time or in vivo clinical applications. 


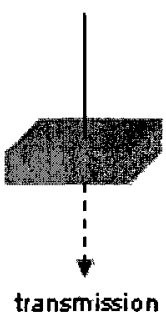

(a) common lab set-up

(b) high sample preparation

(c) ex-vivo applications

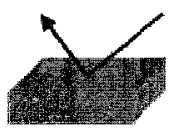

reflection

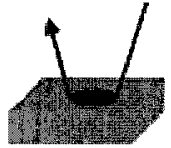

ATR

Figure 2. Different regimes for infrared spectrometry.

\section{Reflectance measurements}

Reflectance measurements are suitable for non-contact measurements (see figure 2).

Light incident on the sample is largely absorbed due to the active nature of compounds in the mid-infrared as discussed above and a small amount is backscattered and specularly reflected, depending on surface morphology and roughness. Backscattered light is captured and transmitted back to a detector where it is measured. In view of the high absorption coefficient of tissues in the mid-infrared and the relative inefficiency in scattering, high intensity of light is needed for reasonable signal-to-noise ratios. Sample preparation requirements vary considerably in this regime. In-vivo applications, such as skin measurements, require as little as cleaning whereas most other applications might require sample extraction and deposition on holders adapted to the measurement equipment. Since this approach yields fairly low signals, it is most suitable for very opaque samples when contact measurement is not possible. 


\section{Attenuated Total Reflectance (ATR) measurements}

This regime has been widely used in the past for chemical analysis. An ATR probe (figure 3) is placed directly in contact with the sample to be measured [3]. Widely used probes are made from diamond because of its physical properties, its inertness, and optical properties in the mid-infrared.

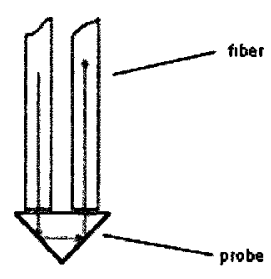

Figure 3. Sketch of an ATR probe.

When incoming light is passed through this probe, it is partially reflected off the sample surface. The portion of the reflected beam that is reflected increases as the angle of incidence of the incident light becomes larger. Beyond a certain critical angle, dependent on the index of refraction of both probe material and the sample, the light is totally reflected and a resulting exponentially decaying wave, referred to as an evanescent wave, is generated within a thin layer of the sample surface. The depth of penetration of the evanescent wave varies depending on the index of refraction of the probe and the angle of the incident radiation and is also wavelength-dependent, increasing with increasing wavelength. For biological tissue, this thickness is generally considered to be on the order of $10 \mu \mathrm{m}$. As a result, if the less dense tissue selectively absorbs certain 
wavelength components of the evanescent radiation, then attenuation of the reflected light occurs preferentially at those absorption bands. The light reflected back into the probe carries this absorption information making absorption spectral measurement possible. This approach is favored for in-vivo applications as it can be performed using relatively small probes placed at the ends of transmitting fibers. Problems with signal-to-noise ratios are also reduced since losses due to backscattering or reflection play no role in the measurement process. An added benefit is also no sample preparation. This can cause problems however with surface contamination given the little penetration depth of midinfrared radiation. In some cases, cleaning the surface of the probe used prior to measurement may be required.

\subsection{Fourier Transform Infrared Spectrometry}

Fourier Transform Infrared (FTIR) spectrometry is widely accepted nowadays in many fields as a reliable and powerful analysis technique. In fact, it has widely become the standard approach for spectral analysis in the mid-infrared range. This section briefly describes the basic design and operation of a Fourier transform spectrometer as well as its main advantages over a traditional dispersive instrument for use in this range.

The basic design of a Fourier transform spectrometer is essentially a Michelson interferometer as shown in figure 4. A beam originating from a point infrared source is first passed through a collimator to render it parallel. The wavefront then passes through a beamsplitter which reflects only half of the beam onto a fixed reflective mirror. The other half of the beam continues to a reflective mirror mounted on a moving platform. 
The two wavefronts are reflected back onto themselves at both mirrors and reach the beamsplitter a second time where they recombine and interfere with each other.

The resulting wavefront is then focused onto a detector that records its intensity. For a monochromatic source, both arms of the beam travel an equidistant path length and arrive in phase at the detector if the movable mirror is placed at the same distance from the beamsplitter as the fixed mirror. If however one arm of the beam is made to travel a distance $d$ such that the difference in the phases is $\pi$ radians, then the two halves of the beam will destructively interfere and the detector will record zero intensity. For this monochromatic source, the resulting intensity of the interference pattern $I(x)$ can be expressed by the familiar two-beam interference relation,

$$
I_{o}(x)=B\left(\sigma_{o}\right)\left[1+\cos \left(2 \pi \sigma_{o} x\right)\right]
$$

where $B\left(\sigma_{o}\right)$ is the intensity of the monochromatic source, $\sigma_{o}$ is the source wavenumber and $x$ is the path difference equal to twice the mirror displacement $d$ 


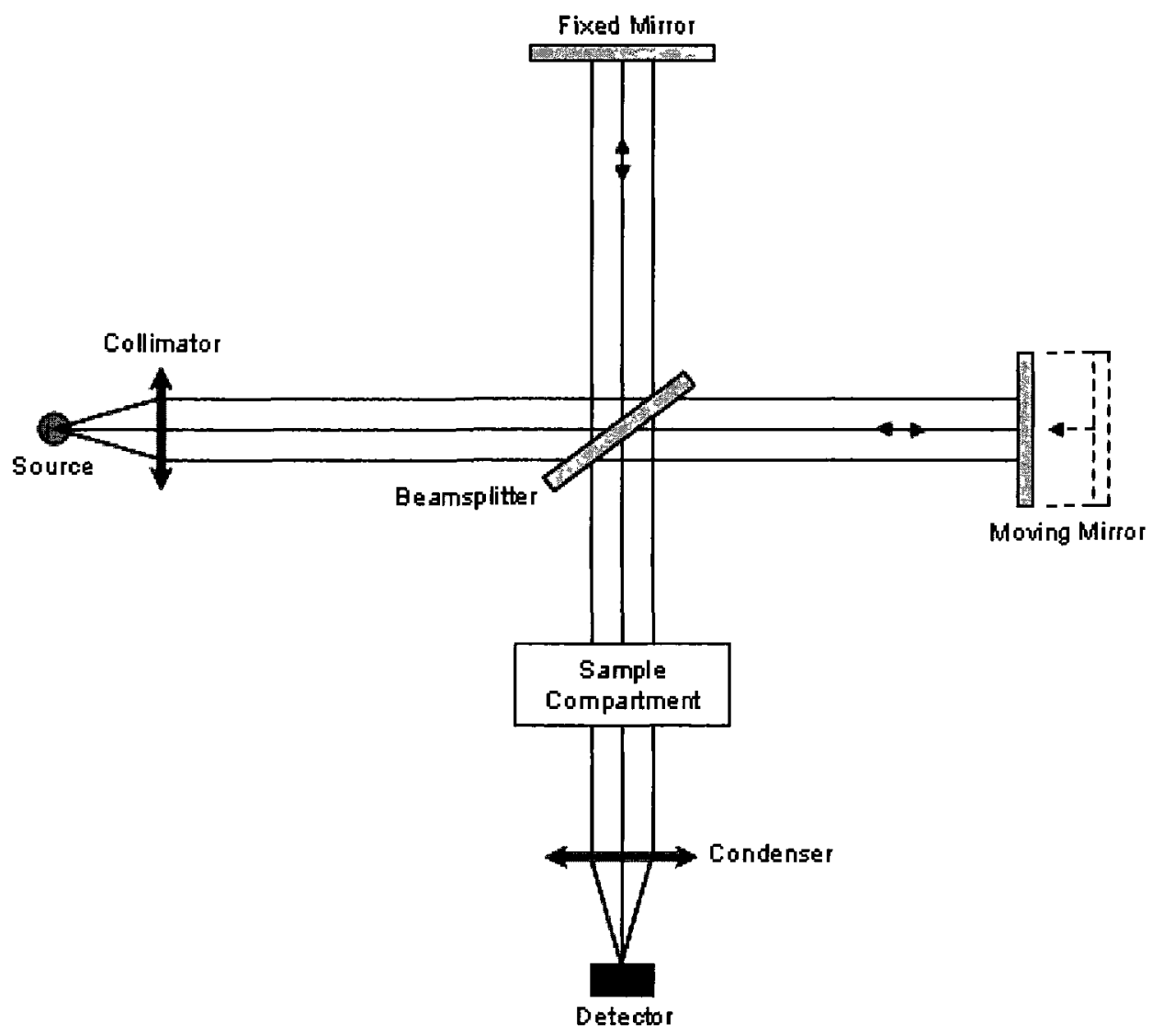

Figure 4. Basic design of a Fourier transform infrared spectrometer.

Thus the distance from the beamsplitter to the mirror can essentially be made arbitrary within the constraints of the coherence length. It is only the path difference traveled between both arms of the beam that will determine the intensity of the recorded signal. For a monochromatic source, the resulting pattern yields a periodic cosine function.

For a polychromatic source such as a heat source, the interference pattern as shown in figure 5 will be a superposition of such cosine functions, 


$$
I^{\prime}(x)=\int_{0}^{\infty} B(\sigma)[1+\cos (2 \pi \sigma x)] d \sigma
$$

If the constant term representing the mean intensity is subtracted, we can write

$$
I(x)=\int_{0}^{\infty} B(\sigma) \cos (2 \pi \sigma x) d \sigma
$$

It follows that the intensity distribution of the source $B(\sigma)$ can be retrieved from the interference pattern $I(x)$ through the inverse Fourier transform,

$$
B(\sigma)=\int_{0}^{\infty} I(x) \cos (2 \pi \sigma x) d x
$$

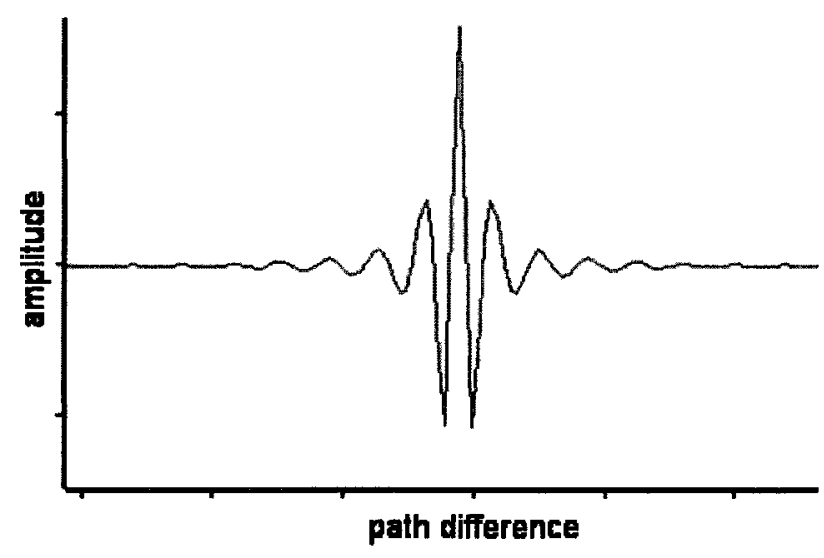

Figure 5. Interferogram showing peak intensity at zero path difference 
From the Fourier transform of the interferogram (amplitude versus path difference plot), one can obtain the frequency (or wavenumber) content of the beam which is incident on the detector. If the envelope of the amplitude is described by a Gaussian function of distance, then the frequency ( or wavenumber) content will also be a Gaussian - but quite a narrow one in the case of a continuous source spectrum.

For spectral absorption investigations, a reading of the source distribution transmitted through all optical components including any sample holders and transmitting fibers is first acquired for use as a reference spectra. This reference spectra measurement is made prior to each sample measurement. When the sample data is acquired, the derived transmitted spectra is used to derive the transmitted coefficient as a function of wavenumber $T(\sigma)$ according to

$$
T(\sigma)=\frac{B(\sigma)}{B_{r}(\sigma)}
$$

where $B_{r}(\sigma)$ is the spectral intensity reading for the reference spectra. The absorption spectra $A(\sigma)$ is then simply

$$
A(\sigma)=1-T(\sigma)
$$


assuming light scattered by the sample is negligible. In the mid-infrared, this assumption is valid given the high level of absorption of molecules. Radiation has little penetration depth in this range as previously discussed.

Fourier transform spectrometers show a few advantages over dispersive spectrometers that make them generally more suitable for use in the mid-infrared range. Of most significance is the multiplexing advantage (or Fellgett advantage after the first investigator who recognized it) [2]. This advantage arises from the fact that a Fourier spectrometer measures all the wavelengths in the signal simultaneously instead of sequentially sampling them as in dispersive designs that use diffraction gratings. This translates into a higher signal-to-noise ratio. This does however assume that most of the resulting noise in the readout is instrument related and that the signal itself is relatively noise free. If this is not the case, as it often is in the visible and ultraviolet, this advantage disappears.

Another is the throughput advantage (or Jacquinot advantage) [2]. Dispersive spectrometers have entrance and exit slits that limit the light that passes through them to reach the detector. Fourier spectrometers do not have this limitation and are limited only by the diameter of the beam originating from the source.

Broad band infrared sources generally do not have high intensity and, as a result of the low levels of energy reaching the detectors, signal-to-noise ratios become very problematic in the mid-infrared. An added complexity is the cost of efficient infrared 
detectors. Dispersive instruments often require a one or two dimensional array of element detectors whereas Fourier instruments only require one large element. As a consequence of the aforementioned advantages, interferometric based designs often show improvements in gain of many orders of magnitude higher than traditional dispersive designs in the mid-infrared region. For this reason, modern infrared spectrometry uses Fourier transform spectrometers almost exclusively.

\subsection{Principles of Fiber-Evanescent-Wave Spectroscopy (FEWS)}

FEWS is based on the same principles as traditional ATR. In FEWS however, an unclad fiber is used as the probe end instead of the typical diamond tip [4]. In this regime, the fiber is put in intimate contact with the sampled tissue and the incident light within the fiber is totally internally reflected at the interface between the fiber and the sample, as shown in figure 6 below. The evanescent wave is attenuated in the same way as in the traditional ATR scheme and carries the absorption information back through the fiber. 


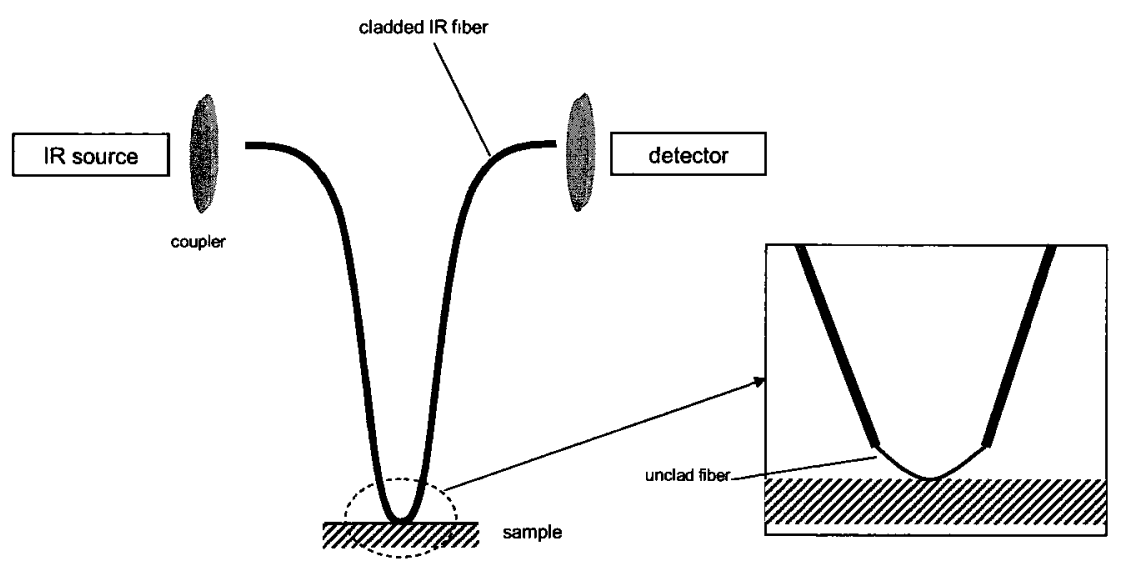

Figure 6. Sketch of the principles of FEWS. A section of the mid-infrared fiber is exposed to the sample tissue. Appropriate bending of the fiber will cause an evanescent wave at the surface to interact with the tissue and attenuate within the absorption bands of the tissue molecules.

It is important to note that the mechanism allowing the absorption reading is different in FEWS than in transmission FTIR spectrometry. The signal reaching the detector in FTIR spectrometry has passed through the sample investigated whereas only the evanescent wave interacts with the sample in the FEWS setup. This must be taken into account when directly comparing spectra from both schemes. Absorption peaks may differ in amplitude from FEWS to FTIR but their intensity relative to other peaks in the spectra should remain constant.

The penetration depth $d_{p}$ of the evanescent wave in the surrounding media is given by [5]

$$
d_{\mathrm{p}}=\frac{\lambda}{2 \pi\left(n_{1}^{2} \sin ^{2} \theta-n_{2}^{2}\right)^{1 / 2}}
$$


where $\lambda$ is the wavelength of the radiation incident on the fiber-tissue interface, $n_{1}$ is the index of refraction of the fiber core, $\theta$ is the incidence angle measured from the normal to the interface and $n_{2}$ is the index of refraction of the outside media. If the incident light is perpendicular to the interface, the penetration depth is very small and in the order of a fraction of its wavelength. Close to the critical angle $\theta_{c}$ given by [6]

$$
\theta_{c}=\arcsin \left(\frac{n_{2}}{n_{1}}\right)
$$

the penetration depth can reach the order of a few wavelengths. Exact penetration in this study is difficult to assess but should be no less than $5 \mu \mathrm{m}$ based on the spectral distribution of the spectrometer light source distribution as presented in the results section below.

FEWS presents both advantages and disadvantages in design and operability. First, a fiber tip is significantly less costly than its ATR probe counterpart. Design of the tip can also be simplified since the same fiber carrying the incident and measurement radiation can be used as the sensing tip by simply removing the cladding around the sensing part. Alternatively, a removable fiber end can also be designed and made disposable $[7,8]$. This has significant advantages when considering in-vivo applications where:

- measurements are made in mixed media with potential contaminants,

- sterilization of the sensing tip is essential,

- aging effects can affect measurements,

- and stability of performance is required. 
Another design simplification is the potential problem of intensity loss across the interface between the transmitting fiber and the probe which is non-existent in the FEWS approach. Disadvantages however lie in the behavior of mid-infrared fibers over time (i.e. aging effects) and their potential reactivity with the tissue sample which is of prime concern in any biomedical application. Again, a disposable tip would have the advantage of solving the aging and deterioration effects in addition to providing a safeguard against transmittable diseases.

Mid-infrared fibers have been studied for about four decades but have only recently reached a development stage where they can be used for broad range transmission and spectroscopy beyond $4 \mu \mathrm{m}$ which would be essential since, as discussed above, many of the fundamental modes of vibrations in organic bonds are found even beyond $10 \mu \mathrm{m}$ [9]. Mid-infrared fibers with transmission beyond $4 \mu \mathrm{m}$ are classified primarily into chalcogenide glass fibers (CIR), polycrystalline fibers (PIR) and hollow waveguides. Table 1 summarizes the important characteristics of each class of IR fibers.

FEWS requires both a broad band source and transmission fiber to accomplish absorption measurements. The more plausible alternatives for the latter are chalcogenide and polycrystalline fibers. Fiber transmission preferably needs to reach close to $20 \mu \mathrm{m}$ for a comprehensive spectroscopic analysis. Polycrystalline fibers seem to be the ideal alternative for this purpose. The following section reviews previous work on infrared 
fibers and demonstrates why the limited numbers of studies that have applied FEWS to biomedical applications have mostly used polycrystalline silver halide fibers.

Table 1. Main characteristics of IR fiber classes.

\begin{tabular}{|c|c|c|}
\hline Whor Type & Adrantages & Wisad vantages \\
\hline $\begin{array}{l}\text { Chalcogenide glass } \\
\text { from As-S or Ge-Se-Te }\end{array}$ & $\begin{array}{l}\text { - transmission up to } \\
10 \mu \mathrm{m} \\
\text { - stable between } 250 \text { - } \\
400 \mathrm{~K} \text {. } \\
\text { - non-hygroscopic }\end{array}$ & $\begin{array}{l}\text { - fragile } \\
\text { - toxic }\end{array}$ \\
\hline Hollow waveguides & $\begin{array}{l}\text { - high transmission } \\
\text { - low divergence } \\
\text { - high damage } \\
\text { threshold } \\
\text { - rugged and durable }\end{array}$ & $\begin{array}{l}\text { - sensitivity to bending } \\
\text { - narrow band } \\
\text { transmission }\end{array}$ \\
\hline $\begin{array}{l}\text { Polycrystalline IR } \\
\text { crystals mostly from } \\
\text { silver halide }\end{array}$ & $\begin{array}{l}\text { - broad transmittance } \\
\text { between 3-18 } \mu \mathrm{m} \\
\text { - non-brittle } \\
\text { - non-toxic } \\
\text { - non-hygroscopic } \\
\text { - stable between 5- } \\
\text { 600 K }\end{array}$ & $\begin{array}{l}\text { - UV sensitive } \\
\text { - aging effects } \\
\text { - corrosive when in } \\
\text { contact with some } \\
\text { metals }\end{array}$ \\
\hline
\end{tabular}




\section{Optical Fibers for Mid-Infrared Transmission}

Mid-infrared transmitting fibers have been the limiting factor in the development of FEWS. Only recently have fibers become capable of satisfying the requirement for broadband transmission well beyond the $10.6 \mu \mathrm{m} \mathrm{CO}_{2}$ laser emission necessary for tissue diagnosis. The following section briefly reviews mid-infrared fibers and provides the main characteristics for fiber types in view of the properties suitable for in-vivo applications including broad transmission range (from $4 \mu \mathrm{m}$ to $18 \mu \mathrm{m}$ ), good aging properties, flexibility, and non-toxicity.

Infrared fibers can be defined as optical fibers transmitting radiation in the spectral range above $2 \mu \mathrm{m}$. The first infrared fibers were produced in the 1960's from chalcogenide glass. The driving motivation for their development rested mostly in thermal imaging and medical applications. Thermal imaging of objects at room temperatures requires detection of blackbody radiation in the $10 \mu \mathrm{m}$ range. An initial driving requirement from the military pushed the development of fibers transparent in this range for transmission of photons to remote photodetectors. An increasing use of $\mathrm{CO}_{2}$ lasers for medical applications also drove the development of these fibers for the $10.6 \mu \mathrm{m}$ laser beam. In the 1970's, a few other types of materials were developed. These included heavy metal fluoride glasses (HMFG), polycrystalline materials and hollow waveguides. Although none offered the same performance as silica based fibers in the near-infrared, they were still promising for short haul applications where transmission was only needed over the range of a few meters. A brief discussion of each of these materials is given below. 
Conventional glass optical fibers in the near-infrared are largely based on silica technology. Silica's extremely low coefficient of thermal expansion allows it to undergo a wide range of temperature changes without significant loss of physical properties. Its mechanical properties also allow low deformation and loss under bending and high resistance to cracking under mechanical stress. Manufacturing processes are also well known and can produce a range of silica variants for specific wavelength optimization. UV grade types have very low metallic impurities making them transparent deeper in the UV range. IR grade types have higher amounts of metallic impurities but their manufacturing aims at reducing water content which has significant absorption lines at $2.2 \mu \mathrm{m}$ and $2.7 \mu \mathrm{m}$. IR grade silica types are however limited to about $3 \mu \mathrm{m}$ range transmisssion.

Although none of the materials developed for the mid-infrared $(2-20 \mu \mathrm{m})$ have optical and physical properties even approaching those of silica in the near-infrared, developments have still led to feasible options for short haul applications. Typical signal losses with silica fibers in the near-infrared are well below $1 \mathrm{~dB} / \mathrm{km}$ whereas most midinfrared fibers are in the range of a few $\mathrm{dB} / \mathrm{m}$. Many also have weak physical properties and may even be toxic. Infrared fibers can be grouped into three broad classes: glass (including chalcogenide and fluoride glasses), hollow (leaky or non-leaky), and crystalline (single crystal and polycrystalline) $[10,11]$. Table 2 depicts this classification with an example of material for each class. 
Table 2. Classification of infrared fibers.

\begin{tabular}{|l|l|l|}
\hline \multirow{2}{*}{ Class } & Type & \\
\hline \multirow{2}{*}{ Glass } & & \\
\hline \multirow{2}{*}{ Hollow } & Chalcogenide & $\mathrm{As}_{2} \mathrm{~S}_{3}$ \\
\cline { 2 - 3 } & Fluoride & ZBLAN \\
\hline \multirow{2}{*}{ Crystalline } & Leaky & Metal coated glass tube \\
\cline { 2 - 3 } & ATR (non-leaky) & Hollow sapphire \\
\hline & Single crystal & Solid sapphire \\
\cline { 2 - 3 } & Polycrystalline & Silver halides \\
\hline
\end{tabular}

Table 3 provides typical values, as reported by Harrington $[12,13]$, of some physical and optical properties of infrared fibers as compared to silica fibers. These values are only approximate since many depend on the exact variant of the type used as well as its manufacturing quality. For example, ART Photonics, Berlin, a leading provider of silver halide fibers has reported losses below $1 \mathrm{~dB} / \mathrm{m}$ up to $10 \mu \mathrm{m}$ [14]. Also, hollow fibers have low loss as reported but often only over the spectral range they are optimized for and under low bending geometries.

Table 3. Physical and optical properties of infrared fibers compared to silica fibers [12].

\begin{tabular}{|l|c|c|c|c|c|c|}
\hline \multicolumn{1}{|c|}{ Property } & \multicolumn{3}{|c|}{ Glass } & \multicolumn{2}{c|}{ Crystal } & Hollow \\
\cline { 2 - 7 } & Silica & $\begin{array}{c}\text { HMFG } \\
(\text { ZBLAN) }\end{array}$ & $\begin{array}{c}\text { Chalcogenide } \\
\text { (AsGeSeTe) }\end{array}$ & $\begin{array}{c}\text { PC } \\
\text { AgBrCl }\end{array}$ & $\begin{array}{c}\text { SC } \\
\text { Sapphire }\end{array}$ & $\begin{array}{c}\text { Hollow } \\
\text { Silica }\end{array}$ \\
\hline $\begin{array}{l}\text { Melting point, } \\
{ }^{\circ} \mathrm{C}\end{array}$ & 1175 & 265 & 245 & 412 & 2030 & 150 \\
\hline $\begin{array}{l}\text { Thermal } \\
\text { expansion, } \\
10^{-6}{ }^{\circ} \mathrm{C}^{-1}\end{array}$ & 0.55 & 17.2 & 15 & 30 & 5 & 0.55 \\
\hline $\begin{array}{l}\text { Refractive } \\
\text { index },(\lambda, \mu \mathrm{m})\end{array}$ & $\begin{array}{c}1.455 \\
(0.70)\end{array}$ & $\begin{array}{l}1.499 \\
(0.6)\end{array}$ & $\begin{array}{c}2.9 \\
(10.6)\end{array}$ & $\begin{array}{c}2.2 \\
(10.6)\end{array}$ & $\begin{array}{c}1.71 \\
(3.0)\end{array}$ & ----- \\
\hline $\begin{array}{l}\text { Transmission } \\
\text { range, } \mu \mathrm{m}\end{array}$ & $0.24-2.0$ & $0.25-4.0$ & $4-11$ & $3-16$ & $0.5-3.1$ & $0.9-25$ \\
\hline $\begin{array}{l}\text { Loss at 2.94 } \\
\mu \mathrm{m} \text { in } \mathrm{dB} / \mathrm{m}\end{array}$ & 800 & 0.08 & 5 & 3 & 0.4 & 0.5 \\
\hline
\end{tabular}




\subsection{Chalcogenide Glasses}

Chalcogenide glasses were the first candidates to be studied for their infrared properties and drawn into fibers in the 1960's. These glasses take their name from the fact that a chalcogen element is used as a substitute for oxygen in conventional oxide glass. One or more of the anion elements $\mathrm{S}, \mathrm{Se}$, and Te are used to form one or multiple-component glass with other elements like As, Ge, Cd, etc. This leads to fundamental vibrational modes shifted farther in the infrared than conventional glass. Among the chalcogenide glasses, $\mathrm{As}_{2} \mathrm{~S}_{3}$ is the most studied and best known. Chalcogenide glasses tend to have high refractive index as shown in table 4 [15]. Their absorption spectra also typically show several sharp peaks as extrinsic contamination of hydrogen, water and $\mathrm{OH}^{-}$bonding is often present $[15,16]$. They are very stable and can be molded into optical glass components such as lenses [17]. They also exhibit a number of photo-induced phenomenon such as photo-darkening, photo-expansion and photo-fluidity when irradiated by the appropriate light. Photosensitivity is usually unfavorable for the application of chalcogenide glasses as optical fibers or fiber lasers. However, it can be useful for manufacturing photonic crystals, optical memory devices, and microstructures for integrated optics such as waveguides [18]. Their highly non-linear properties also make them useful as optical amplifiers. Their application however for medical purposes has been limited due to their high content of toxic elements like As and Se. Below are described in more detail the main forms of chalcogenide fibers currently studied. 
Table 4. Example refractive indices for various chalcogenide compositions [15].

\begin{tabular}{|c|c|}
\hline $\begin{array}{c}\text { Glass composition } \\
\text { (molar ratio) }\end{array}$ & $\begin{array}{c}n \\
\text { (at 633 nm) }\end{array}$ \\
\hline $\mathrm{As}_{40} \mathrm{~S}_{60}$ & 2.598 \\
\hline $\mathrm{Ge}_{33.3} \mathrm{~S}_{66.7}$ & 2.137 \\
\hline $65 \mathrm{SrS}-35 \mathrm{Ga}_{2} \mathrm{~S}_{3}$ & 2.169 \\
\hline $65 \mathrm{BaS}-35 \mathrm{Ga}_{2} \mathrm{~S}_{3}$ & 2.194 \\
\hline $30 \mathrm{La}_{2} \mathrm{~S}_{3}-70 \mathrm{Ga}_{2} \mathrm{~S}_{3}$ & 2.471 \\
\hline
\end{tabular}

\section{2. $A s_{2} S_{3}$ and $A s_{2} S_{3}$}

Sundaram and his colleagues have studied the As-S-Se family of chalcogenide glasses in detail [19]. Possible compositions formed are listed in Table 5 in molar ratio. The compositions were chosen to study the transmission property trends as a function of element abundance. The major observations drawn from their study can be summarized as follows:

- Compositions with higher Se content have flatter transmission curves above $8 \mu \mathrm{m}$.

- Absorption peaks below $8 \mu \mathrm{m}$ are attributed to contamination by the source chemicals for sulfur.

- The highest overall transmission in the 8-12 $\mu \mathrm{m}$ window was achieved with arsenic triselenide $\left(\mathrm{As}_{2} \mathrm{Se}_{3}\right)$. Arsenic trisulfide only showed better transmission below $9 \mu \mathrm{m}$ and then showed a sharp drop off. $\mathrm{As}_{40} \mathrm{~S}_{20} \mathrm{Se}_{40}$ showed a steadier drop off and it is believed that if the oxygen contamination can be reduced, $\mathrm{As}_{40} \mathrm{~S}_{20} \mathrm{Se}_{40}$ may have better transmission than $\mathrm{As}_{40} \mathrm{Se}_{60}$ in the 8-12 $\mu \mathrm{m}$ window. 
Table 5. As-S-Se family studied by Sundaram et al [19].

\begin{tabular}{|c|c|}
\hline As-S system & $\begin{array}{c}\text { As-Se and As-S-Se } \\
\text { systems }\end{array}$ \\
\hline $\mathrm{As}_{30} \mathrm{~S}_{70}$ & $\mathrm{As}_{40} \mathrm{Se}_{60}$ \\
\hline $\mathrm{As}_{33} \mathrm{~S}_{67}$ & $\mathrm{As}_{40} \mathrm{~S}_{40} \mathrm{Se}_{20}$ \\
\hline $\mathrm{As}_{35} \mathrm{~S}_{65}$ & $\mathrm{As}_{40} \mathrm{O}_{30} \mathrm{Se}_{30}$ \\
\hline $\mathrm{As}_{40} \mathrm{~S}_{60}$ & $\mathrm{As}_{40} \mathrm{~S}_{20} \mathrm{Se}_{40}$ \\
\hline $\mathrm{As}_{44} \mathrm{~S}_{55}$ & $\mathrm{As}_{24} \mathrm{~S}_{38} \mathrm{Se}_{38}$ \\
\hline
\end{tabular}

\subsection{Ga-La-Na and Other Non-toxic Sulphides}

Shephard and his colleagues have investigated mixtures of Ga-La-Na-S glasses for their transmissions in the $2-5 \mu \mathrm{m}$ range for active and passive applications [20]. Originally, Ga-La-S compositions were created but it was found that the addition of $\mathrm{La}_{2} \mathrm{O}_{3}$ as a substitute for some of the $\mathrm{La}_{2} \mathrm{~S}_{3}$ to produce Ga-La-S-O composition could improve fiber manufacturing but the presence of oxygen hampered transmission in the mid-infrared. More recently, work was done on Ga-La-Na-S systems to optimize transmission. Glasses with varying amount of $\mathrm{Ga}_{2} \mathrm{~S}_{3}, \mathrm{La}_{2} \mathrm{~S}_{3}$ and $\mathrm{Na}_{2} \mathrm{~S}$ were made.

All glasses showed some contamination of $\mathrm{OH}$ which is believed to cause a small absorption peak at $2.9 \mu \mathrm{m}$. Absorption around $8.6 \mu \mathrm{m}$ is thought to be due to oxide contamination. This absorption might be improved but transmission will ultimately remain for application below $6 \mu \mathrm{m}$.

Other sulphides containing alkaline-earth, rare-earth, germanium and gallium have been studied as well. Like other sulphide glasses, they also have high refractive indices ranging from 2 to 2.5 , contain no arsenic and range in transmission from the visible to 
almost $10 \mu \mathrm{m}$. Their higher melting and transition temperatures also allow high power laser delivery applications.

Takebe and colleagues [15] studied the transmission spectra in the visible and infrared of a series of these glasses. In the visible range, the absorption edge is located in the 400 to $500 \mathrm{~nm}$ range. In the mid-infrared, the low phonon energy of the glass networks allows transmission potentially up to $12 \mu \mathrm{m}$. However, impurities originating from raw materials and the glass preparation processes often introduce $\mathrm{OH}$ or oxygen contaminations and impair transmission above $8 \mu \mathrm{m}$. These problems are common across all types of chalcogenide fibers. Ge-S glasses for example have theoretical transmission up to $15 \mu \mathrm{m}$ but show marked drop offs above $8 \mu \mathrm{m}$ when manufactured into fibers because of the contamination factors.

\subsection{Fluoride Glasses}

Heavy metal fluoride glasses (HMFG) were accidentally discovered in 1975 at the University of Rennes. Those that have been drawn in to fibers are mostly the fluorozirconate $\left(\mathrm{ZrF}_{4}-\mathrm{BaF}_{2}-\mathrm{LaF}_{3}-\mathrm{AlF}_{3}-\mathrm{NaF}\right.$ or $\left.\mathrm{ZBLAN}\right)$ and fluoroaluminate glasses $\left(\mathrm{AlF}_{3}-\mathrm{ZrF}_{4}-\mathrm{BaF}_{2}-\mathrm{CaF}_{2}-\mathrm{YF}_{3}\right)[21]$.

Their development was initially motivated by the promise of a wider transmission range and lower loss in the IR as compared to silica. In fact, theoretical losses for fluoride glasses at $2.6 \mu \mathrm{m}$ are around $0.001 \mathrm{~dB} / \mathrm{km}$, which orders of magnitudes less than silica at 
this range. Their transmittance also spreads from the UV to the mid-infrared with an index of refraction close to 1.5 remaining stable across wavelength and temperature. A low refractive index also entails lower Fresnel losses at the fiber ends (less than 4\%). Bending characteristics are also very good. Fibers with a $125 \mu \mathrm{m}$ core have bend radii of less than $0.5 \mathrm{~cm}$. Figure 7 shows the transmission of multimodal fluoride glasses currently commercially available from IR Photonics based in Montreal, Canada [22]. A sharp decrease in transmittance occurs beyond $3.5 \mu \mathrm{m}$.

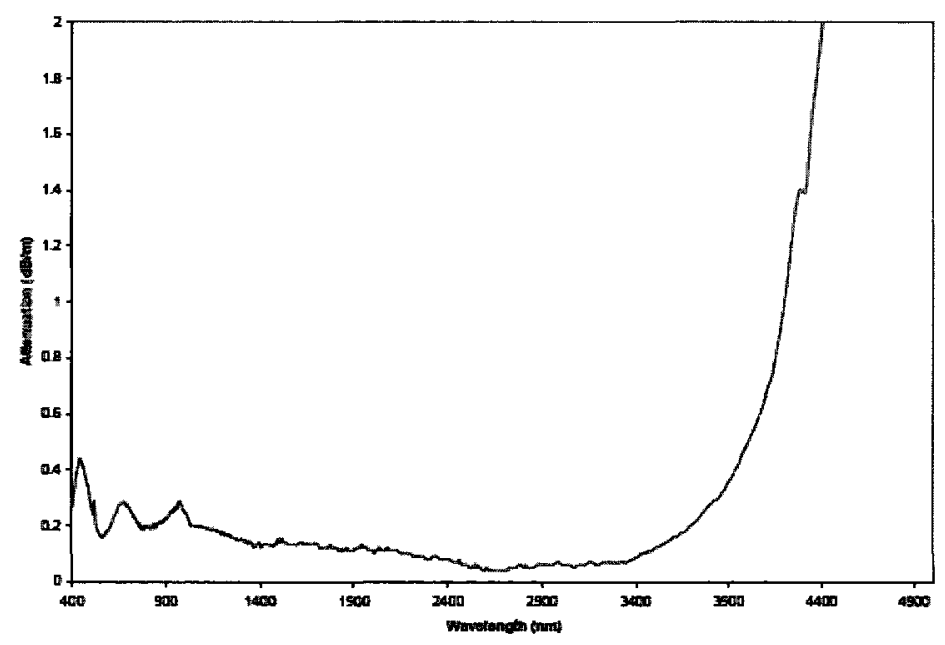

Figure 7. Attenuation curve for fluoride glass fibers reported by IR Photonics [22].

Theoretical transmissions have never been achieved due to the manufacturing difficulties of fluoride glasses. These fibers cannot be made by vapor deposition which is the most suitable technique for the preparation of ultra-high-quality performs and fibers. They must be prepared by melting and casting. Crystallization occurs very rapidly as the molten glass is cooled down resulting in core-clad interface irregularities, formation of bubbles, and small preform sizes. Higher quality fibers can be achieved in a micro- 
gravity environment as found on board orbiting spacecraft but any such manufacturing beyond small scale scientific studies is obviously prohibitive. The stability of fluoride fibers' physical properties depends greatly on protective layering as it is very sensitive to atmospheric moisture. Protection requires adequate sleeving and sheathing of the fiber or pretreatment of the preform to reduce surface crystallization. Such fibers have been successfully used in industry over many years.

Though the performance of fluoride glass fibers has been recognized, their use will inevitably be limited to applications requiring efficient transmission between $2 \mu \mathrm{m}$ and 4 $\mu \mathrm{m}$. Silica may be favored for applications below $2 \mu \mathrm{m}$ and losses are too high above 4 $\mu \mathrm{m}$. A range of applications are still possible though. With the development of both YAG lasers (Nd:YAG, Ho:YAG, and Er:YAG) and $\mathrm{CO}_{2}$ lasers, applications for dental and medical purposes require transmission in the $2-5 \mu \mathrm{m}$. For example, Erbium-doped YAG lasers are becoming increasingly used for dentistry, skin resurfacing and urology because their $2.9 \mu \mathrm{m}$ beam corresponds to a peak in water absorption. Fluoride glasses may be the best alternative in this case given the limited transmission of virtually all the other materials. They can also appropriately be used to transmit a pointing beam in the visible range to guide surgical procedure. In applications where thermal measurements need to be made from the near to mid infrared, fluoride glasses are the only alternative able to span the whole range. Finally, another good example is their use for fiber lasers. Fluoride glasses can contain rare-earth-element concentrations higher than silica or chalcogenide glasses which increases the material's lasing efficiency. 


\subsection{Germanium oxides}

Another type of heavy metal oxide glass can be briefly mentioned. Germanium oxide $\left(\mathrm{GeO}_{2}\right)$ fibers have found some use in the high power laser delivery in the $3 \mu \mathrm{m}$ range [12]. This type of fiber has a very high glass transition temperature, is very flexible, durable and non-toxic. In these aspects, it is superior to fluoride fibers and is better suited to handle high power laser energy, although losses are altogether higher than for fluoride fibers.

\subsection{Hollow Waveguides}

Hollow waveguides present a unique and interesting alternative to conventional solid core fiber designs. As their name suggests, they consist of a plastic, glass, or metal tube generally coated on its inner surface. They are very similar in design and working principle to microwave guides. There are two main classes of hollow waveguide designs: (a) leaky guides having metallic and dielectric inner coatings with $n>1$ and (b) the ATR guides with dielectric tubing of $\mathrm{n}<1$ [13]. The ATR guides behave similarly to other solid core fibers since the material that forms the tube has an index of refraction less than the air core allowing total internal reflection. An index lower than $n=1$ is possible near the absorption resonance of some materials. This does not imply that light travels faster than the speed of light in this range since the index of refraction is defined by the phase velocity of the wave and not by the group velocity. 
The prime advantages of hollow waveguides derive from the air core that allot high power can be delivered through these waveguides. Their simple structural design also has the potential of low manufacturing cost. With proper design, they can also be made to transmit over $20 \mu \mathrm{m}$. Disadvantages however also arise from the core. The most significant are high losses with both decreasing waveguide radius size and decreasing bending radius (a small bend radius entails greater flexing of the guide) [12], which make these fibers more sensitive to flexing than other fibers. The attenuation factor $\alpha$ dependence on the bore radius $a$ has been shown to be $\alpha \sim 1 / a^{3}$. The losses due to bending have been shown to vary as $1 / R$ where $R$ is the bending radius. Smoothness of the inner surface also plays an important factor in determining overall attenuation due to scattering effects at the interface with coatings. Smoothness comes into play because fabrication processes for different types of tubing lead to varying surface roughness.

Hollow waveguide designs have varied considerably. Most have a circular cross-section but work has been done in the past with rectangular cross-sections as well. The disadvantage of the rectangular cross-section is a non-uniform bending capability but offer the potential of less loss in transmission. Metallic waveguides have been pioneered by Miyagi and his colleagues and can serve as a good example of this type of guide [23]. They used an aluminum tube coated first by a dielectric, then a metallic film and finally by a thicker nickel layer. The aluminum was then etched away. Optimization for different wavelengths was achieved through control of the thickness layer of the dielectric coating. 
Plastic tubing has also been used with dielectric and metallic coatings. Croitoru and his colleagues from the University of Tel Aviv have pioneered this approach by using Teflon and polyethylene tubing [24]. These types of tubing can transmit lower laser power thresholds but do have the potential of having lower fabrication costs and are durable enough for moderate power usage typically around $25 \mathrm{~W}$. In addition, bore sizes manufactured from plastic tubing have been typically larger than metallic or glass tubing.

Finally, glass tubing has become a very popular alternative because of its ease in fabrication, its flexibility and most importantly the smoothness of its inner surface. The glass of choice used by Harrington and his colleagues at Rutgers University and other groups has been silica [13]. The bore sizes achievable are range between 250 and 1000 $\mu \mathrm{m}$. Control of the wavelength propagation properties is achieved by varying the thickness of the dielectric coating as in the metallic and plastic designs. The metal coat has typically been $\mathrm{Ag}$ underlying a dielectric coat of AgI (as used by Harrington).

Miyagi's group has taken a slightly different approach. The glass tube acts as the dielectric material in this case (silica is again proposed) and is coated on the outside with a Ag film to lower losses and optically shield the glass tube $[25,26]$. Finally, a protective layer of thick metal or hard plastic encases the tube for practical handling purposes.

\section{Hollow $n<1$ Waveguides}

Waveguides with an index of refraction lower than 1 behave like conventional fibers through internal reflection since the material itself has an index of refraction lower than 
the air core within the transmission range [13]. This is possible because some materials in a specific range (close to absorption bands) have an index lower than one. This does not counter any postulates of Relativity which states that no information carrying signal can travel faster than $c$, the speed of light. The index of refraction is defined by the ratio of $c$ to the phase velocity of light in the medium. Information is carried through the group velocity which cannot be greater than the speed of light. Cases where the phase velocity of a wave in a medium is actually greater than $c$ are not so uncommon. For example, sapphire has $n<1$ from 10 to $16.7 \mu \mathrm{m}$. Single-crystal sapphire hollow tubes are now manufactured and sold commercially by Saphikon, Milford, $\mathrm{NH}$, in bore sizes ranging from 250 to $1070 \mathrm{~nm}$. Other than sapphire tubing, there are no significant developments which have been very successful in this type of waveguide. Problems with high extinction coefficients in other materials have led to the general abandonment of research in this area in favor for other alternatives.

\subsection{Polycrystalline Fibers}

An obstacle to the development of all crystalline fibers over the years has been the difficulty in their fabrication. Many halide crystals have excellent infrared transmission but only few have the required physical properties, such as ductility and low melting point, to be drawn into fibers through hot extrusion, the process of choice for this type of material [27]. Thallium and silver have been the metals used for this purpose. An early fiber made of TlBrI, named KRS-5 by Hughes Research Labs, was thought to hold great promise for application in the infrared beyond $20 \mu \mathrm{m}$ because it had very low theoretical 
losses. Its development was however abandoned when these losses were never achieved. The toxicity of $\mathrm{Tl}$ also became an issue and silver halides showed better performance and flexibility.

The $\mathrm{Ag}-\mathrm{Br}-\mathrm{Cl}$ compositions have now become the best polycrystalline fibers for the infrared $[10,14]$. Some of the fabrication difficulties have been overcome and these fibers now represent the best alternative for broadband transmission beyond the chalcogenide limit of about $10 \mu \mathrm{m}$. Theoretically, pure silver halides have transmission starting from $0.5 \mu \mathrm{m}$ below which absorption is due to band to band electronic transitions. Transmission from this lower limit is high up to $30 \mu \mathrm{m}$, above which phonon absorption becomes important. This broad optical window is unique among infrared materials and was the motivation for the efforts in development. In addition, silver halides have favorable physical properties, including ductility and plasticity.

A series of papers were published in the 1980s and 1990s studying the physical properties in depth including hardness, elastic limit, fatigue, and lifetimes [28-42]. Many of these properties follow a parabolic type curve as a function of composition with $\mathrm{AgCl}$ at one end and $\mathrm{AgBr}$ at the other, with a $50 / 50$ mix of $\mathrm{Br}$ and $\mathrm{Cl}\left(\mathrm{AgCl}_{0.5} \mathrm{Br}_{0.5}\right)$ showing a peak. Several studies have shown that even after several hundred bending cycles of a radius even as small $5 \mathrm{~cm}$, no significant degradation in optical properties could be seen. Some issues have been raised regarding the fibers' photosensitivity to UV and visible light. Saito has however shown that through proper use of polymer coatings, the photodarkening effect can be resolved [43]. Coatings can also protect the fibers from 
corrosive interaction with other metals. Their relatively low melting point however does set limits on how much power can be delivered by them. Laser power of $30 \mathrm{~W}$ in a continuous wave is feasible for regular operation. Clearly, silver halides are well suited for most of the applications in the medical and industrial fields.

The most notable laboratories in the world researching the development of silver halide fibers are those of the General Physics Institute (GPI) in Moscow and Tel Aviv University in Israel. Although GPI was a pioneering institute in this area and has a very strong heritage in silver halide fabrication, not much has been published since most of their work was done in the Soviet era. Much of the publications pertaining to silver halides and their development come from the Tel Aviv University which currently boasts a leading center of excellence in academic research in the field. Of note, three fiber design concepts common for conventional silica fibers have been attempted for silver halide material. These include graded-index fibers, photonic crystal fibers and segmented cladding fibers.

Fabrication of graded-index silver halide fibers was attempted with the hope of reducing losses as compared to step index fibers [44]. Silver halide fibers tend to have rough surfaces at the interface with their cladding. This significantly increases scattering in the interface and results in transmission losses. Graded-index fibers were believed to improve transmission by reducing the sharp drop in refractive index at the interface and thus minimizing its effect on scattering. The process used to make the graded fiber was the rod-in-tube method whereby a tube is drilled in an original Cl-rich preform and a rod, 
composed of a Br-rich silver halide is inserted into it and placed in an oven at high temperatures. During this heating, $\mathrm{Cl}$ ions diffuse into the rod populating the volume close to the surface with $\mathrm{Cl}$ ions and creating the radial gradient in refractive index desired. This rod is then extruded to form the graded-index fibers.

Results from Dekel and Katzir showed an improvement in signal losses for these fibers as compared to core/clad step-index fibers but these were still higher than for the step-index core-only fibers. Losses were measured at about $4 \mathrm{~dB} / \mathrm{m}$ depending on the diameter of the fibers and the time of diffusion allowed in the fabrication process. Problems were caused mainly from the fabrication process. It was very difficult to achieve a uniform cross-sectional distribution along the fiber. There was also an asymmetry in the radial cross-sectional distribution.

Another approach taken was the fabrication of photonic crystal fibers aiming at creating a low-loss single mode (SM) silver halide fiber $[45,46]$. SM fibers have been very difficult to fabricate because they require small diameters and a small difference in refractive index with the cladding. As previously mentioned, silver halide cores have a rough surface which leads to high scattering at the interface with the clad. Reducing the core diameter also entails a lower transmitted power through the fiber which already suffers from high attenuation even at larger dimensions. For these reasons, Rave and his colleagues at Tel Aviv University fabricated photonic crystal fibers made of silver halides having periodic concentric rings around the core center. The procedure consisted of 
extruding a preform made of alternating concentric rings of other preforms made of AgCl-core/AgBr-clad.

Fabrication techniques in the end proved too difficult to warrant continued efforts, so in an attempt to improve results, Millo and his colleagues at the same center chose the alternative approach of segmented cladding fibers $[47,48]$. In this design, the core of the fiber has a high refractive index and the cladding is made of alternating regions of high and low refractive index thereby creating a radial gradient for the effective total refractive index. This gradient index is also wavelength dependent thereby also providing a useful modal dispersion of the fiber. The material and angular variations of the cladding can be controlled and optimized. These fibers were fabricated using the same extrusion process as above but with preforms shaped to fit the geometry required. In their initial attempts, Millo and his colleagues used angular dimensions of $40^{\circ}$ for the wider segments of lower refractive index $(n=2.1176)$ and $20^{\circ}$ for the thinner section of lower refractive index $(n=2.1108)$. Both materials were a composition of $\mathrm{Ag}-\mathrm{Cl}-\mathrm{Br}$ with a differing concentration of $\mathrm{Cl}$ and $\mathrm{Br}$ of the order of $5 \%$. The fiber losses were measured on a $1 \mathrm{~m}$ long fiber and found to be $16.5 \mathrm{~dB} / \mathrm{m}$ at $10.6 \mu \mathrm{m}$. With improvements in extrusion techniques and reduced deformations, segmented cladding fibers promise to be the best alternative for low loss single mode fibers for the mid-infrared with a large spectral transmission range. 


\section{Mid-Infrared Tissue Response}

\subsection{Mid-Infrared}

Diagnosis based on the spectral response in the infrared requires an understanding of the spectral response of tissues. This in turn requires an understanding of the composition of the tissues at the molecular level as well as their structural patterns. For the mid-infrared range, knowledge of the major cell types and chemical species present in different tissues is vital to interpret any spectral signature.

The human body is essentially composed of water, lipids, proteins, nucleic acids and carbohydrates [49]. From these about 200 types of cells are created which then form only four basic types of tissues. These are: epithelial, connective, muscular and nervous tissues. Epithelial tissues are an aggregation of polyhedral cells that adhere together to make large sheets used for surface coverage such as skin, inner surfaces of blood vessels and gastrointestinal tracts. Connective tissue is largely made up of an extracellular matrix excreted by cells. It is composed mainly of protein fibers and specialized cells used for binding. Hard tissues such as bone and cartilage are grouped in this category. Nervous tissues on the other hand are mainly formed of neurons, responsible for the transmission of electrical impulses, and glial cells which support and nourish them. Finally, muscle tissue forms a large part of the body mass and is responsible for all types of motions in and of the body. Each organ in the body is composed of some varying proportions of each of these tissues. 
On a biochemical level, the amide group (composed of a carbonyl $\mathrm{C}=\mathrm{O}$ linked to a nitrogen $\mathrm{N}$ ) absorptions play a major role in the spectral response of tissue in this range. Absorptions in the higher wavenumbers include the bands between 2800 and $3000 \mathrm{~cm}^{-1}$, which arise from the $\mathrm{CH}_{3}\left(2956 \mathrm{~cm}^{-1}\right.$ and $\left.2871 \mathrm{~cm}^{-1}\right)$ and $\mathrm{CH}_{2}\left(2922\right.$ and $\left.2851 \mathrm{~cm}^{-1}\right)$ asymmetric and symmetric stretching vibrations and strong $\mathrm{O}-\mathrm{H}$ stretching band of water ( 3000 to $3400 \mathrm{~cm}^{-1}$ ). Absorptions in the wavenumbers below $2000 \mathrm{~cm}^{-1}$ are due to routinely found features in tissue such as $\mathrm{C}=\mathrm{O}$ stretching vibrations $\left(1740 \mathrm{~cm}^{-1}\right)$ and nucleic acids $\left(1714 \mathrm{~cm}^{-1}\right), \mathrm{CH}_{2}$ scissoring and $\mathrm{CH}_{3}$ asymmetric bending vibrations of lipids, proteins, and nucleic acids (1450 to $\left.1480 \mathrm{~cm}^{-1}\right), \mathrm{COO}^{-}$symmetric stretching vibrations of fatty and amino acids $\left(1400 \mathrm{~cm}^{-1}\right)$ and $\mathrm{PO}_{2}{ }^{-}$asymmetric $\left(1225 \mathrm{~cm}^{-1}\right)$ and symmetric $\left(1084 \mathrm{~cm}^{-1}\right)$ stretching vibrations of nucleic acids and phospholipids.

A detailed review of the mid-infrared active bond vibrations relevant to tissue diagnosis has been given by Movasaghi et al.[9]. In the range $900 \mathrm{~cm}^{-1}$ to $1800 \mathrm{~cm}^{-1}$ of interest in this study, the absorption spectra can be grouped into three main sections. Glycogen is mainly responsible for features detected between $1000 \mathrm{~cm}^{-1}$ to about $1200 \mathrm{~cm}^{-1}$. In the $1200 \mathrm{~cm}^{-1}$ to $1500 \mathrm{~cm}^{-1}$ range, the features can be attributed to a mix of proteins, nucleic acids, and collagen. Finally, proteins are responsible for the strong peaks between 1500 $\mathrm{cm}^{-1}$ and $1700 \mathrm{~cm}^{-1}$. Levels of glycogen have been documented in the published literature to decrease significantly with abnormal transformation of cells leading to a parallel drop in the absorption levels between $1000 \mathrm{~cm}^{-1}$ and $1200 \mathrm{~cm}^{-1}$. Proteins on the other hand have been found to be more stable throughout abnormal transformation. This translates 
to more stable peaks in the $1500 \mathrm{~cm}^{-1}$ to $1700 \mathrm{~cm}^{-1}$ range that can be used for normalizing purposes when analyzing a single spectrum or spectral comparison between samples.

\subsection{Review of Research on the use of FTIR for the Detection of Malignant Cells}

Dysplasic transformations within a cell entail drastic changes of its physical and biochemical makeup. This includes mutations involving the breakdown of molecular bonds within DNA as well as the formation of new ones. The hypothesis put forward by authors investigating mid-infrared spectrometry for malignancy diagnosis is that the absorbed infrared radiation will reflect these changes and can, if well interpreted, provide information on tissue health.

Wong et al. [50] first reported evidence of spectral changes in the infrared absorption of cervical cells due to carcinogenesis using FTIR spectrometry. Exfoliated cervical cells collected from 156 females were assessed by pathologists and infrared absorption readings were acquired. Several key spectral changes including intensity changes and peak shifts were consistently noted between malignant and normal tissue. Changes in the malignant samples have been associated with changes in glycogen levels, the hydrogenation of the phosphate $\left(\mathrm{PO}_{2}^{-}\right)$groups, and changes in the $\mathrm{C}-\mathrm{O}$ stretching bands. Furthermore, there was evidence that dysplastic response (i.e. the response of tissue undergoing dysplasia) showed identical but less intense spectral changes from the malignant extreme. 
Wong et al. [51] also carried out research on exfoliated cells and tissues from endocervix and ectocervix by ATR-FTIR spectroscopy. Measurements were made of the transmission spectra of exfoliated endocervical mucin-producing columnar epithial cells and the ATR infrared spectra of the single-columnar cell layer on the endocervical tissues. Comparisons were then made with the corresponding infrared spectra of the ectocervical squamous cells and squamous epithelium. Authors demonstrated that, in contrast to traditional FTIR, ATR-FTIR is a more desirable method to obtain meaningful spectral information due to the contamination of connective tissue on the endocervical epithelium tissue. It was also shown that, although a significant decrease in glycogen content is evident in malignant tissue, no single feature could lead to a proper classification of malignancy.

Fung et al. [52] reported on the FTIR transmission spectroscopic response of endometrial tissue of 17 female patients. The FTIR technique used also took into account the dependence of the measurements on the pressure applied by the probe during spectral acquisition (referred to as pressure-tuning FTIR). The spectra of normal tissues differed from those of grade I and grade III adenocarcinoma. In the malignant samples, changes were observed in the symmetric and asymmetric stretching bands of the phosphodiester of the backbones of nucleic acids, the $\mathrm{CH}$ stretching bands, the $\mathrm{C}-\mathrm{O}$ stretching bands of the $\mathrm{C}-\mathrm{OH}$ groups of carbohydrates and cellular protein residuals, and the pressure dependence of the $\mathrm{CH}_{2}$ stretching mode. These findings agree with previous results reported by Wong et al [50]. 
Following this line of work, Wood et al. [53] visually classified spectra from 272 patients based on the intensity of the glycogen bands $\left(1022 \mathrm{~cm}^{-1}\right.$ and $\left.1150 \mathrm{~cm}^{-1}\right)$, being higher in normal cells, and pronounced symmetric phosphate stretch at $1078 \mathrm{~cm}^{-1}$ for normal cells in contrast to both symmetric and asymmetric stretch for malignant cells. Comparison of this simple classification was made with Pap smear results. A Principal Component Analysis (PCA) was done and showed general classification agreement.

Cohenford et al.[54] also investigated the FTIR spectra of women with normal cells, dysplasic cells and squamous cell carcinoma. It was observed that the spectra of normalappearing intermediate and superficial cells of the cervix from women with either dysplasia or cancer differed from normal women in a continuum fashion that paralleled the transition from normal to malignancy. The findings reiterated the suggestion that the structural changes underlying the spectroscopic changes are involved in or are a product of cervical carcinogenesis. In this and other studies, Cohenford et al. [55] also relied on the use of Principal Component Analysis (PCA) for spectral data processing.

Chiriboga et al. [56, 57] reported on observed variation of spectral signatures in different layers of cervical squamous tissue and their use to monitor cell maturation and differentiation. Spectral comparative work was also done on biopsies of cervical squamous epithelium and exfoliated cervical cells. Results show a wide range of contributing factors that can confound interpretation of the spectral signatures. Thus, 
proper development of a diagnostic methodology can only come from a good understanding of these confounding factors.

In this line of thought, Wood et al. [58] studied a series of factors which were thought to potentially confound spectral interpretation. Variables such as the presence of leukocytes and fibroblasts were found to potentially show features that can be similar to those reported as malignancy indicators. The use of ethanol in sample preparation was also found to artificially retain levels of glycogens in the cells. Others agents such as seminal fluids, erythrocytes and endocervical mucin also affect the features linked to malignancy but can also be detectable by other unique features which could serve to spectrally isolate them. This work did show potentially confounding factors and raised the issue of their specific effects on potential diagnosis.

Wong et al. [59] further detailed confounding factors that can lead to misinterpretation. An account was given of the spectral effects of polymorphs, cell degradation, and impurities including endocervical columnar cells, metaplastic cells, cervical mucus, red cells, and debris. To avoid high rates of false positives, it was found that these effects must be removed from the measured spectra. This was done through spectral subtraction in this work. In one application of the methodology to 250 patients in a dysplasia clinic who reported negative smears, thirty were found to be false negatives through this IR spectroscopic technique. Of these, twenty patients had follow-up smears performed and six patients showed positive abnormal smears. 
More recently, Sindhupak et al. [60] found consistent results during their study on the use of FTIR spectroscopy for cervical cancer detection on Thai women. The study included results from 275 females of which 108 showed positive results in malignancy tests. The objective of their study was to examine the mid-infrared signatures through FTIR spectroscopy and assess the method as a diagnostic tool compared to Pap smears and histological diagnosis. Results confirmed many of the previous findings by Wong et al. regarding changes in spectral features from normal to malignant cancer. When compared to Pap smears, Sindhuphak's group claims excellent correlation and predictive capacity. Findings claimed for sensitivity and specificity of FTIR results versus histology are slightly over $96 \%$.

As a follow-up, Wood et al. [61] studied 2-dimensional FTIR spectral mapping as a means of differentiating tissue types found in squamous cervical epithelium at different stages of disease using multivariate unsupervised hierarchical cluster methods. They collected samples from 10 different patients and imaged a large number of tissue regions which were then classified using through statistical cluster analysis. The purpose of the work was to demonstrate the ability of FTIR imaging to distinguish tissue types and suggest its potential use as a diagnostic tool for cervical screening.

A study was carried out by Mordechai et a1.[62] on formalin-fixed melanoma and cervical cancer cells by FTIR microspectroscopy to detect common biomarkers between them. The spectra were analyzed for changes in levels of RNA, DNA, phosphates, and carbohydrates. Of note was the ratio of RNA/DNA as measured at $1121 / 1020 \mathrm{~cm}^{-1}$ that 
showed a similar trend between normal and malignant tissue in both types of cancer suggesting the existence of common spectral biomarkers across different cancer types.

Mark et al. [63] also investigated the application of FTIR microspectroscopy. Biopsies were used to assign the correct stage of premalignancy in patients with symptoms of cervical intraepithelial neoplasia. An evaluation was made on the FTIR spectra for different grades of neoplasia using probabilistic neural networks and histology. Results indicated a differentiation between the normal and malignant cells with accuracy.

Bogomolny et al.[64] also studied FTIR microspectroscopy as a tool for early detection of changes accompanying malignant transformation. Cells in culture were infected by the murine sarcoma virus known to induce malignant transformation and spectrally analyzed at various post-infection time intervals in order to identify consistent and significant biomarkers that can differentiate malignant cells from normal ones. Spectral analysis was done using cluster analysis and discriminant classification function techniques. Interestingly, results showed that the first spectral changes are detectable earlier than the first morphological signs of cell transformation.

\subsection{A Note on Sample Preparation}

Two differing methodologies for sample preparation were generally used in the studies to date, such as the above-referenced publications. 
The first methodology, used by Wong et al. [50] consists of dividing the tissue into two. The part used for histological examination was fixed in $10 \%$ neutral buffered formalin. The other part used for FTIR investigation is immediately placed in saline solution and frozen at $-80^{\circ} \mathrm{C}$ after collection and kept at that temperature until used. When measurements are to be made, the samples are thawed and vortexed until well mixed. They are then centrifuged for several minutes at speeds of at least 6000 RPM until separation of the tissue from the saline solution is achieved. The sample is then smeared on an infrared transparent slide and cool-air dried.

The other method used by Wood and Chirigoba [56-58] and colleagues, as well as others referenced above, consists of retrieving samples that were formalin-fixed paraffinpreserved (FFPP) after collection. The samples must then be de-waxed using a series of solvents such as xylene and ethanol.

Most tissue studies undertaken in vibrational spectroscopy (both Raman and infrared spectroscopy) used this latter procedure given the plentiful supply of archival FFPP tissue samples available. Frozen tissue samples, although considered the gold standard, are more difficult to obtain.

If these processing methodologies result in changes in bands identified as diagnostically significant, implications would be serious for the proper development of infrared spectroscopy as a clinical tool. Faolan et al. [65] studied the potential effects of tissue processing on human tissue sections following investigations by Pleshko et al. [66] and 
others. It was generally found that although it bears a close resemblance to fresh tissue, processed tissue has undergone many biochemical changes. In the context of FTIR spectroscopy, it was found that freezing resulted in loss of intensity and a shift of the amide I and II bands, which was thought to be a result of a depolymerisation of the cellular cytoskeleton known to occur in the cryogenics field. Formalin fixation produced a shift of $10 \mathrm{~cm}^{-1}$ in the same amide I and II bands, which was also found with the use of ethanol. Freezing and formalin fixation also lead to a reduction in the $1398 \mathrm{~cm}^{-1}$ band $\left(\mathrm{C}=\mathrm{O}\right.$ symmetric stretch). Xylene resulted in an increase of the 1239 and $1454 \mathrm{~cm}^{-1}$ bands. The FTIR signature of wax at $1465 \mathrm{~cm}^{-1}$ was also noticed indicating that typical de-waxing protocols are not fully effective. It was recommended that this band not be used for diagnostic purposes in FFPP samples. Sample de-waxing also decreased the overall intensity of the spectra.

Though these effects show biochemical changes occurring in processed tissue, diagnostic features in other parts of the spectrum can still be found. Further studies are required to better ascertain the effects of these processing methods, especially when several potentially spectrally-active steps are involved as is the case with FFPP samples. Freezing showed less alterations in the spectra and may be better understood given general experience in the cryogenics field.

It is very important that the spectral work conducted take into account the contributions made by the processing techniques particularly when FFPP samples are used in conjunction with automated classification techniques such as those used by most 
investigated referenced above. Unfortunately no mention of these effects is made in the reports reviewed herein.

\subsection{FTIR-FEWS Studies on Biosample Analysis}

Advances in mid-infrared fiber optics and hardware are slowly making it feasible to consider in vivo investigations of malignancy in human tissue. As discussed above, FTIR-FEWS is expected to allow such investigations. It has to date been applied in several in vitro and ex vivo studies but the only in vivo studies have been carried out on skin because of ease of access $[67,68]$. In-vivo measurements were made on the lips, scalp, and other parts of the body to assess skin health and topical creams. It was shown that the FTIR-FEWS approach can show the ability to follow the in-vivo levels of lipids, hydration and triglycerides following application of skin treatments [69-74].

Makanos et al. [75] collected spectra from biopsy samples of colonic mucosa of 37 human patients with the aim of differentiating cells that were normal, hyperplasic and dysplasic. Subtle differences in the spectra were observed. Partial least square discriminant analysis was used for classification. Results were compared with histology and showed levels of predictive values of $82 \%$.

Bindig et al. $[7,70,76]$ completed studies involving the acquisition of spectra from silver halide fiber probes as well as spectral maps using a microspectrometer of colorectal, bladder and mouse skin tissue samples. Fresh samples were used from biopsies that were 
rapidly cooled in liquid nitrogen and cryosectioned without the use fixation or freezing media to avoid possible spectral alterations. After the tissue samples were imaged and probed by the silver halide ATR fiber, they were stained and examined by pathologists. Results were compared and both spectral mapping and fiber evanescent wave data showed good predictive values for malignancy compared to normal.

A limited number of studies such as those above have been performed on select types of tissue through FEWS. However, to the best of the author's knowledge, no real in vivo work has been performed to assess the feasibility of detecting malignant changes in any human tissue using the mid-infrared range. As well, no studies have been found addressing changes in cervical tissues using FEWS in either in vivo or ex vivo fashion.

\subsection{Important Biochemical Markers}

Analysis of the spectral response in this study was based on parameters established by Wong et al. Several key changes in the infrared absorption characteristics were observed between malignant, dysplastic and normal exfoliated tissue [50], consisting of a change in intensity at a particular wavelength, a shift in the wavelength where an absorption occurs, and in some cases the appearance of a new absorption peak. A pressure dependence on the spectral response was also observed but is outside the scope of this project.

In their work, Wong et al. reported the following changes in malignant exfoliated tissue as compared to normal and dysplasic specimens: 
a) severe change in the intensity of the bands at $\sim 1025 \mathrm{~cm}^{-1}, \sim 1047 \mathrm{~cm}^{-1}, \sim$ $1082 \mathrm{~cm}^{-1}, \sim 1155 \mathrm{~cm}^{-1}, \sim 1244 \mathrm{~cm}^{-1}$, and $\sim 1303 \mathrm{~cm}^{-1}$, and

b) a significant shift of the bands at $\sim 1025 \mathrm{~cm}^{-1}, \sim 1047 \mathrm{~cm}^{-1}, \sim 1082 \mathrm{~cm}^{-1}$, and $~$ $1155 \mathrm{~cm}^{-1}$ and

c) a new band peak at $\sim 970 \mathrm{~cm}^{-1}$.

Most bands have been assigned to vibrational mode changes in the main functional groups consisting of nucleic acids, proteins, glycogen, lipids and collagen. The main contributing groups responsible for the changes noted above are summarized in table 6 . More detailed description of band assignments can be found elsewhere [9].

Table 6. Main contributors to the spectral changes observed.

\begin{tabular}{|c|c|c|}
\hline Balds $\left(\mathrm{cm}^{-1}\right)$ & & I \\
\hline 970 & PO4- stretching & Nucleic acids and proteins \\
\hline 1025,1047 & $\begin{array}{l}-\mathrm{CH} 2 \mathrm{OH} \text { groups } \\
\text { - } \mathrm{C}-\mathrm{O} \text { stretching coupled } \\
\text { with the } \mathrm{C}-\mathrm{O} \text { bending of } \\
\text { the } \mathrm{C}-\mathrm{OH} \text { groups }\end{array}$ & Glycogen \\
\hline 1082 & PO2-stretching & Nucleic acids \\
\hline 1155 & $\mathrm{C}-\mathrm{O}$ stretching & Glycogen and proteins \\
\hline 1244 & Amide III & Collagen \\
\hline 1303 & $?$ & Collagen \\
\hline
\end{tabular}

Wong et al. also studied the effects of several potentially confounding factors that may interfere with the accurate diagnosis of malignancy. As reported earlier, these factors included polymorph effects, cellular degradation and other impurities such as endocervical columnar cells, cervical mucus, metaplastic cells, red blood cells and debris 
from spatulas and brushes that could be used for sample retrieval. Of these, the factors that could most significantly affect analysis were the presence of polymorphs, cellular degradation and cervical mucus.

The spectrum of pure polymorph cells does not show the bands at 1023,1080 , and 1155 $\mathrm{cm}^{-1}$, that are strong indicators of glycogen content, but is similar otherwise. Therefore when a sample of healthy cells contains polymorphs, its spectrum will show a seeming lower glycogen content which could be interpreted as an indicator of malignancy. This effect could however be compensated for by proper spectral subtraction of the polymorph signal.

The presence of mucus shows a similar effect. The relative intensity of the $1023 \mathrm{~cm}^{-1}$ band to the $1082 \mathrm{~cm}^{-1}$ band is decreased while the effects on other parts of the infrared spectra remain minimal. This also can be confounded with a decrease in glycogen levels that can mislead interpretation.

Cellular degradation is of prime importance. Even if placed in saline solution, cell samples must be kept at low temperatures to avoid any degradation. After two hours, cells at room temperature show marked similarity to malignant cells. Over drying cell samples prior to measurement may also lead to degradation. There are however unique features to degraded cells such as the broadening of the $1023 \mathrm{~cm}^{-1}$ glycogen band. These unique features permit the early filtration of degraded spectra in the analysis. 
The totality of these finding were integrated into a software package by Dr. Patrick Wong allowing a diagnosis based on the aforementioned parameters. The analysis in this study was carried out using this software. Details of exactly how and which band ratios and peak shifts are used cannot be disclaimed here due to Intellectual Property issues related to the software. Comments have been kept general in this regard throughout this report. 


\section{Data}

\subsection{Experimental Apparatus}

A dedicated series of equipment was acquired and installed in our laboratory for use in this study. Figure 8 shows the overview of the equipment consisting of:

- a Clean-Ceil (Microzone Corporation, Ottawa, CA) fumehood (a)

- a Vortex-Genie (Scientific Industries, Bohemia, NY) vortex (b)

- an Eppendorf (Hamburg, Germany) centrifuge (c)

- a Bomem MB-104 series (ABB, Quebec City, CA) FTIR spectrometer (d)

- a nitrogen cooled MCT (ABB, Quebec City, CA) detector (e)

- a Balston (Parker Blaston, Haverhill, MA) air generator (f)
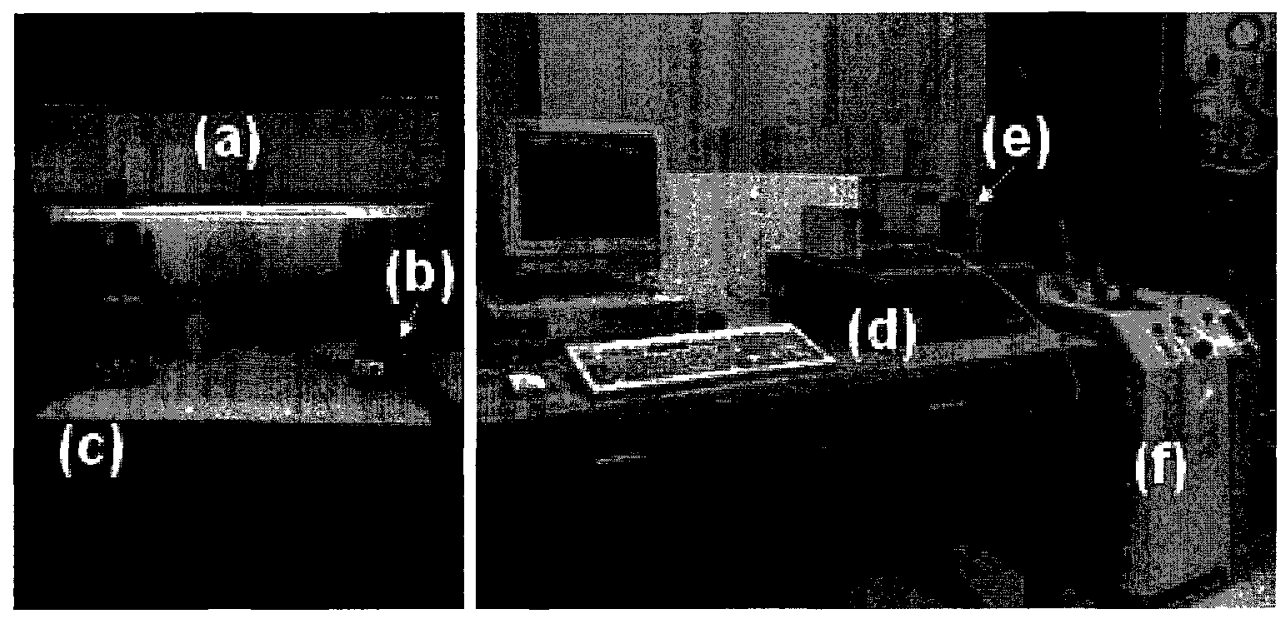

Figure 8. Apparatus setup.

Sample spectra were acquired on both a specially designed silicon sample holder, shown in figure 9(a), and a silver halide fiber probe, shown in figure 9(b). Both required different mounting techniques onto the spectrometer. 


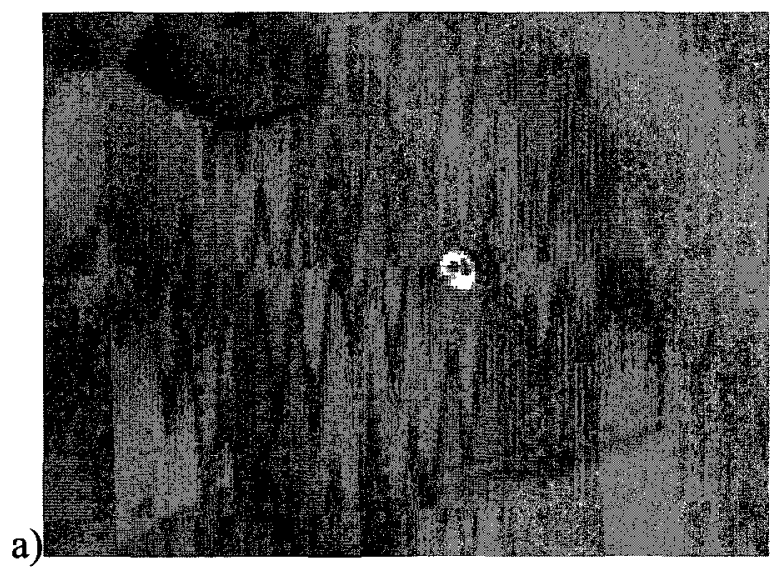

b)

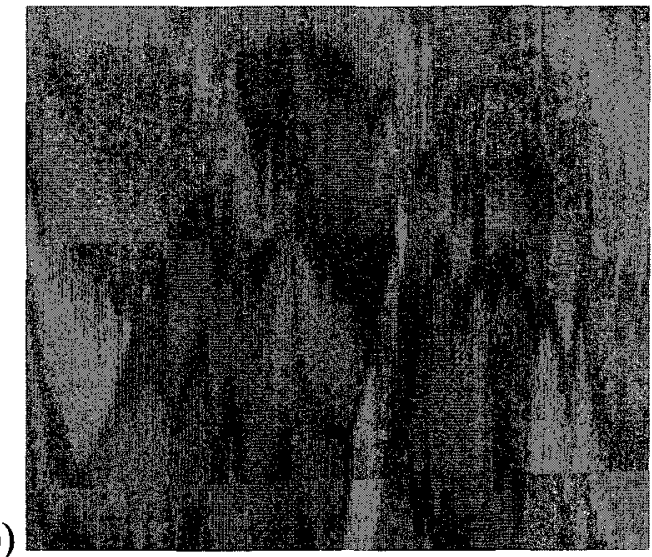

Figure 9. a) silicon sample slide holder; b) fiber probe.

The coupling of the silver halide fiber required very delicate alignment. First an adjustable platform was custom designed to mount a Fibermate optical coupler (Harrick Scientific, Pleasantville, NY) to the Bomem spectrometer. This platform allowed 3dimensional linear adjustments to help align the coupler with the aperture from the spectrometer. The input section of the optical coupler consists of a fixed flat mirror that directs the beam onto a rotating flat mirror that allows some degree of fine alignment adjustment (see figure 10). This mirror directs the beam onto a concave fixed mirror that focuses it onto the fiber end. The light then travels through the fiber to the probe end in contact with the sample. The output section layout of the coupler that redirects the light from the fiber back into the spectrometer is identical to the input. 


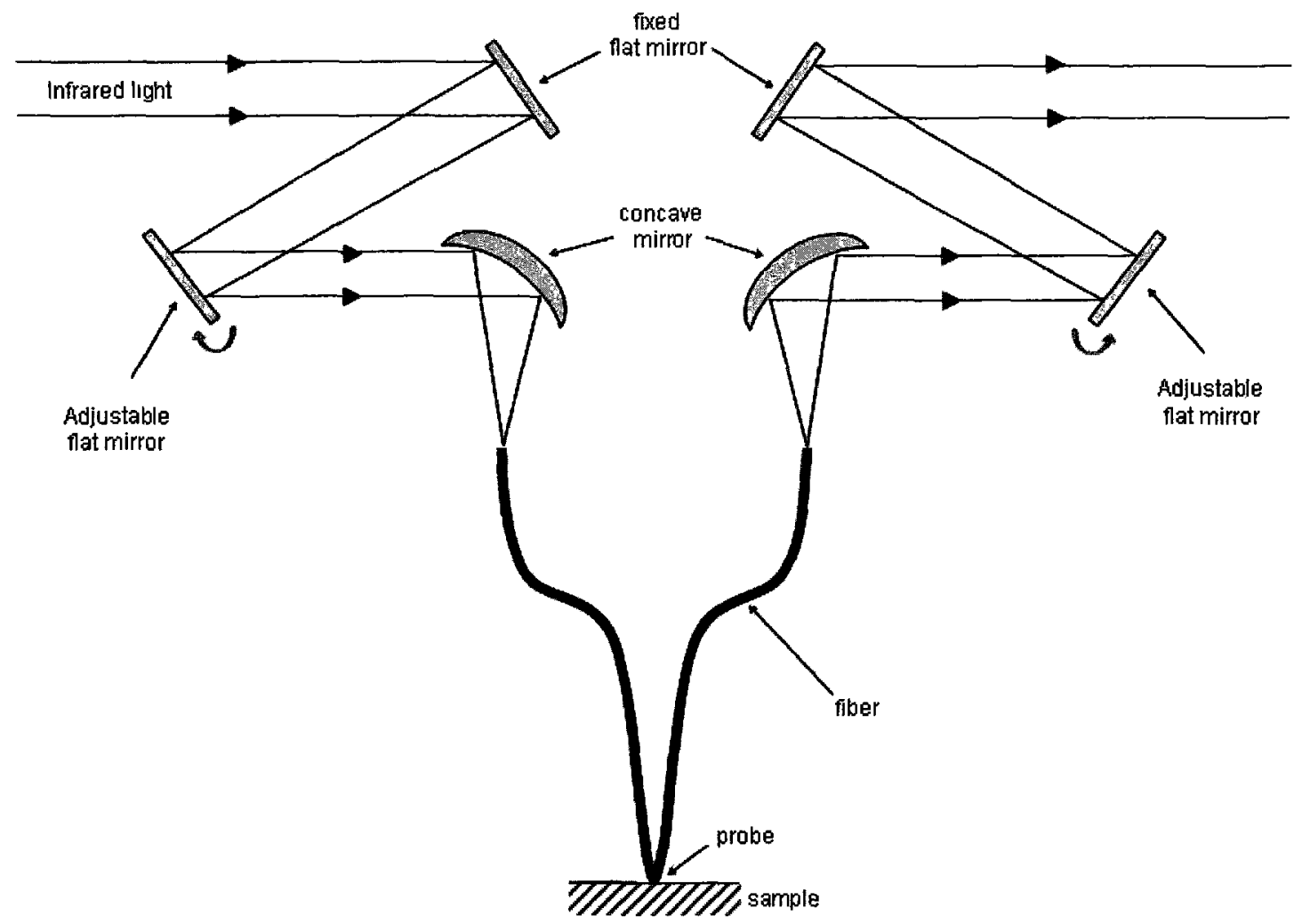

Figure 10. Optical path traversed through the fiber-coupler assembly.

Proper alignment was very time consuming given the weak infrared intensity of the spectrometer source. No good means of tracking the light through its optical path was available making the fine adjustments extremely challenging. In fact, the radiation at the exit aperture of the spectrometer (pior to its entrance into the coupler) could only be detected through exposure of a liquid crystal film sensitive to thermal radiation. The film was first cooled through contact with a thin vessel containing liquid nitrogen to enhance its sensitivity. This however was of limited use as the film could not detect the light after a short distance of travel. In the end, successful alignment was only achieved after a $\mathrm{CO}_{2}$ laser was brought into operation and used as the source to independently align the fiber- 
coupler assembly prior to mounting onto the spectrometer. Tracking the laser through the optical path was readily achieved with the use of fluorescent film sensitive in the narrow bandwidth of the $10.6 \mu \mathrm{m} \mathrm{CO} 2$ emission. Once the optical components were aligned, the fiber-coupler assembly was mounted onto the movable platform and brought into alignment with the spectrometer exit aperture using the cooled liquid crystal film.

\subsection{Methodology}

Twenty-three cervical samples were received from Dr. Patrick Wong of the University of Ottawa. These samples were collected from patients throughout a series of initiatives undertaken over a period of about two years in the late 1990s. Samples of the cervical cells were collected and placed in normal saline solution and immediately frozen $(-80$ $\left.{ }^{\circ} \mathrm{C}\right)$. They were kept at these temperatures until measurements were made for this study.

All work for sample preparation was carried out inside the fumehood. The tube containing the tissue was first placed at room temperature and allowed to thaw completely over a period of ten minutes. The tube was then vortexed long enough to ensure good mixing of the sample. It was then centrifuged at a minimum of $5000 \mathrm{rpm}$ for at least 6 minutes. The supernatant was carefully removed by simple capillary action using a pipette. The sample was then separated into two parts for investigations using the specially designed silicon sample holder [77] and the silver halide probe.

The FTIR spectrometer was then set up with the sample holder plate, and background readings of the silicon sample holder were taken. Prior to each sample measurement, a 
reference spectra was acquired of the sample holder (or the fiber probe) used in order to derive the absorption spectra from the transmitted energy reaching the detector. This ensures that any absorption observed in the resulting spectra is solely due to the sample. The wet specimen was then spread on the silicon sample holder and dried for about 2 minutes at room temperature with forced air. Once dry, the sample was taken to the FTIR spectrometer and absorption spectra were acquired over the period of one minute at a resolution of $4 \mathrm{~cm}^{-1}$. Multiple spectra were taken to ensure repeatability. The amount of absorbed radiation is directly proportional to the sample thickness on the slide. This does translate into a baseline offset change in the absorption spectrum but does not change the location of absorption peaks. Care was taken to keep the thickness of the sample to a minimum to ensure good signal at the detector while covering as much of the area exposed to the infrared light for measurement.

The spectrometer was then set up with the fiber coupling assembly and background readings were acquired of the fiber probe. The other part of the wet sample was then smeared over the probe end and dried in the same manner as the silicon sample holder. Multiple spectra were then acquired with the same parameters as mentioned above for the silicon sample holder. Sample thickness in this case does not have the same impact as with the transmission setup since it does not affect the depth of penetration of the evanescent wave. 
Spectra acquired were classified based on work done by Wong et al. [50] as references above. A software package supplied by Dr. Patrick Wong performed automated classification of the spectra based on these biomarkers.

\subsection{Results}

In this section, results for all samples analyzed are presented. Each sample was processed by the software package developed by Wong et al. [78] that contains all classification parameters discussed previously and provides a diagnosis termed normal $(\mathrm{N})$, abnormal $(\mathrm{Ab})$ or degraded. A 'normal' diagnosis implies a healthy tissue sample whereas 'abnormal' indicates a sample showing dysplastic or malignant features. Some samples showed degraded signatures which rendered them invalid. Table 7 shows the results for all samples. Of the 23 samples, only 12 samples showed spectra that were classified as not degraded for both the transmission FTIR and FEWS measurements. Causes for degradation rest largely in the sample preparation procedures and are discussed below. It is of note that most degradation was recorded in the earlier samples when preparation methodologies were still being practiced and perfected. 
Table 7. Classification results: shaded blocks indicate degraded spectra. ' $\mathrm{N}$ ' is for normal and " $\mathrm{Ab}$ " stands for abnormal.

\begin{tabular}{|c|c|c|}
\hline Sample & Probe & Slide \\
\hline 1 & TH & 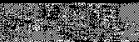 \\
\hline 2 & $N$ & (6) \\
\hline 3 & $\bar{N}$ & $4=1$ \\
\hline 4 & S & 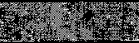 \\
\hline 5 & (3) & $\mathrm{AB}$ \\
\hline 6 & $y^{2} \cdot 1$ & 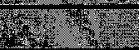 \\
\hline 7 & 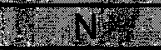 & $A b$ \\
\hline 8 & $A b$ & $A b$ \\
\hline 9 & ${ }^{3} \mathrm{M} / \mathrm{N}$ & $\overline{A b}$ \\
\hline 10 & $A b$ & $\overline{A b}$ \\
\hline 11 & $A b$ & $A b$ \\
\hline 12 & $A b$ & $\mathrm{Ab}$ \\
\hline 13 & $7 x^{2}$ & \\
\hline 14 & $N$ & $\mathrm{~N}$ \\
\hline 15 & $\bar{N}$ & $\overline{\mathrm{N}}$ \\
\hline 16 & $\mathrm{~N}$ & 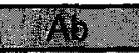 \\
\hline 17 & $\mathrm{AlO}$. & 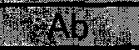 \\
\hline 18 & $\mathrm{Ab}$ & $\mathrm{Ab}$ \\
\hline 19 & $\overline{A b}$ & $\overline{A b}$ \\
\hline 20 & $A b$ & $A b$ \\
\hline 21 & $\overline{A b}$ & $\overline{A b}$ \\
\hline 22 & $\overline{A b}$ & $\overline{A b}$ \\
\hline 23 & 8 (1) & Alo \\
\hline
\end{tabular}

All but one non-degraded spectra show the same classification for both the traditional slide transmission and FEWS approaches. A more detailed discussion of these results follows. In light of the importance of water absorption in this region of the spectrum, water effects and the impact of sample drying are discussed immediately after a presentation of data errors and repeatability applicable to all spectra acquired. This is followed by a presentation of the absorption characteristics and possible impact of the silver halide fiber and silicon sample holder used. To exemplify typical spectral measurements in both protocols, four samples are then presented. The first shows readouts of normal healthy tissue and the second as clearly abnormal. The third sample 
demonstrates spectral degradation. The fourth discusses sample 9 that showed a varying diagnosis between both measuring techniques.

\section{Data Error and Repeatability}

In order to gauge the errors associated with the spectra acquired and to ensure their repeatability, a few samples of which two examples are given below were measured repeatedly over a short and long timescale. Both examples below have been performed using the FTIR transmission setup but are also representative of the FEWS setup as similar changes were observed in both cases. Figure 11 shows three consecutive absorption spectra for sample 15 taken over three minutes, each requiring an acquisition time of one minute with the Bomem spectrometer. It is clear from the graph that little variation is detected in this timescale as all peaks overlap very well and the greatest amplitude difference in absorption coefficient is about 0.15 near the $930 \mathrm{~cm}-1$ peak. 


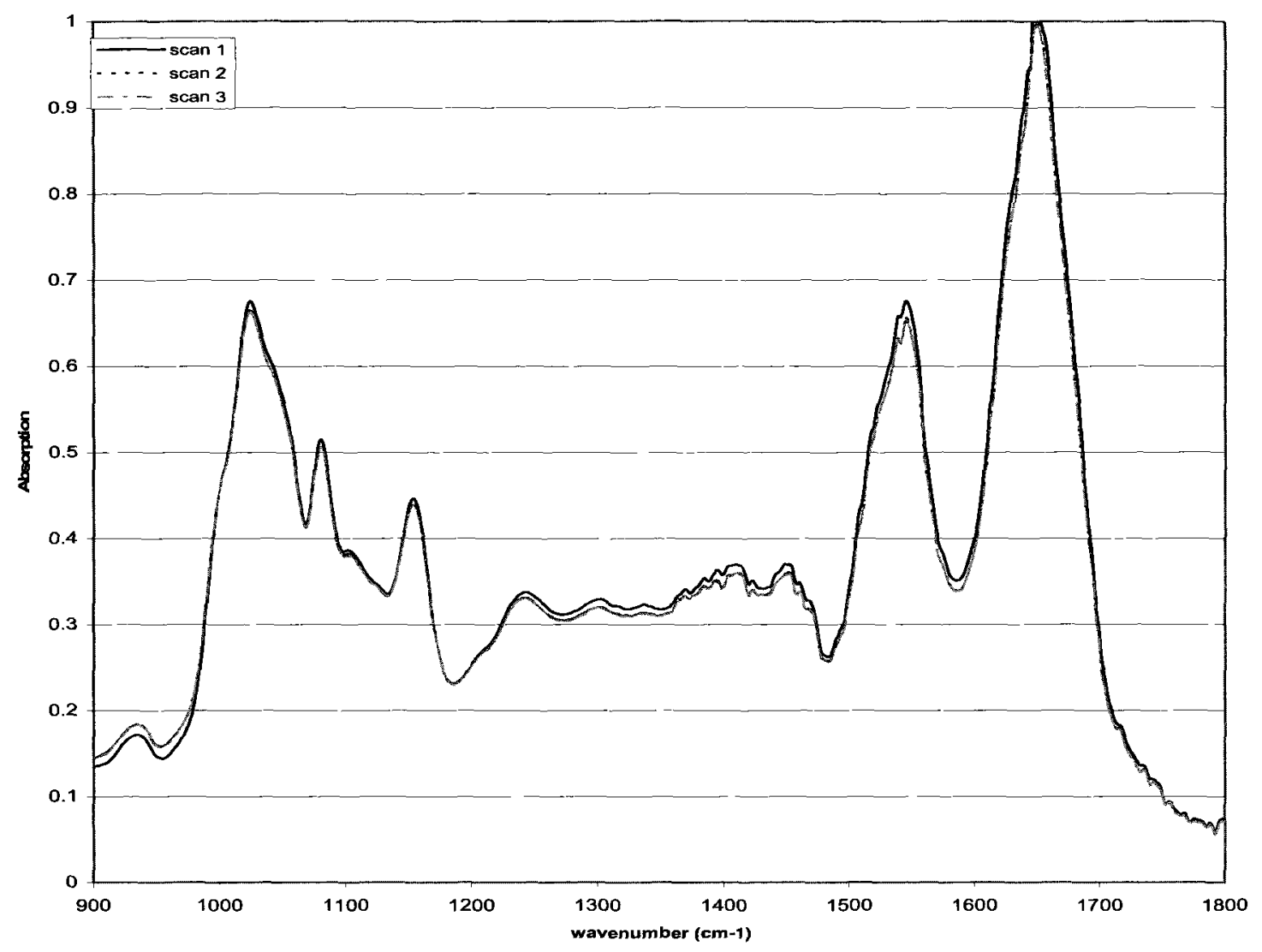

Figure 11. Consecutive spectral acquisitions of sample 15.

Absorption changes over the span of 30 minutes were also investigated. Figure 12 shows the absorption spectra of sample 16 acquired over this timescale as well as a reading taken after 24 hours. Scan 1 was completed immediately after sample preparation and each subsequent scan 2 and 3 were completed at ten minute intervals. Each spectrum was again acquired over one minute using the Bomem spectrometer. A slight increase in the absorption intensity, mostly occurring in the first ten minutes, is noted over this timescale but no significant changes occur to the absorption peaks. The change within the first few minutes may be explained by possible detector signal drift as it was not recorded in other cases. 


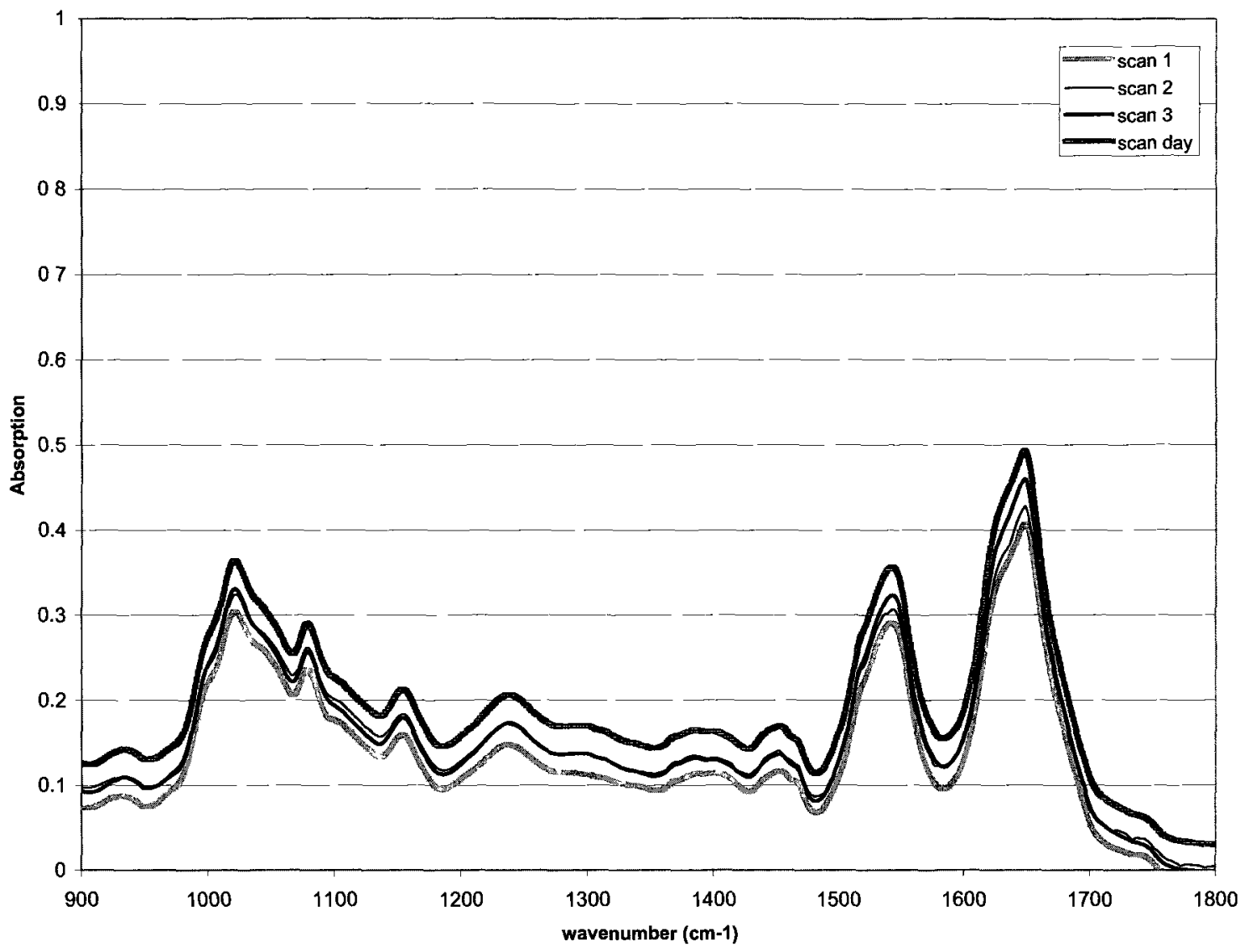

Figure 12, Spectral absorption variations over long time scale of sample 16.

Given the variance in the data, it is considered safe in this study to use the spectra acquired within a few minutes after sample preparation over the same time period of one minute. All subsequent spectra shown herein have been acquired in this manner. 


\section{Water Absorption}

To better understand the effects of water content in the sample during spectral absorption measurement, a series of spectral acquisitions were taken on samples with varying degree of water removed. Figure 13 below shows the absorption of water as measured by the FEWS methodology. Mid-infrared spectroscopy has always been regarded as problematic due to high absorption of water at these ranges. Whereas this is certainly the case in the traditional transmission setup where even little water completely cuts off transmitted radiation, it would appear to be less so in the FEWS approach. Radiation through the fiber tends to remain in the fiber and does get transmitted whereas only the evanescent wave interacts with the water in contact with the fiber probe and seemingly keeps a good signal-to-noise ratio. Although the radiation through the fiber cannot penetrate into layers of high water content tissue, it can nonetheless acquire a good signal of the superficial layers. In figure 13, an average of about $15 \%$ was absorbed across the $900-1800 \mathrm{~cm}^{-1}$ range with a maximum of almost $40 \%$ at $1650 \mathrm{~cm}^{-1}$. Most features referred to above are below this peak where absorption levels seem rather constant, thus introducing little artificial absorption peaks. 


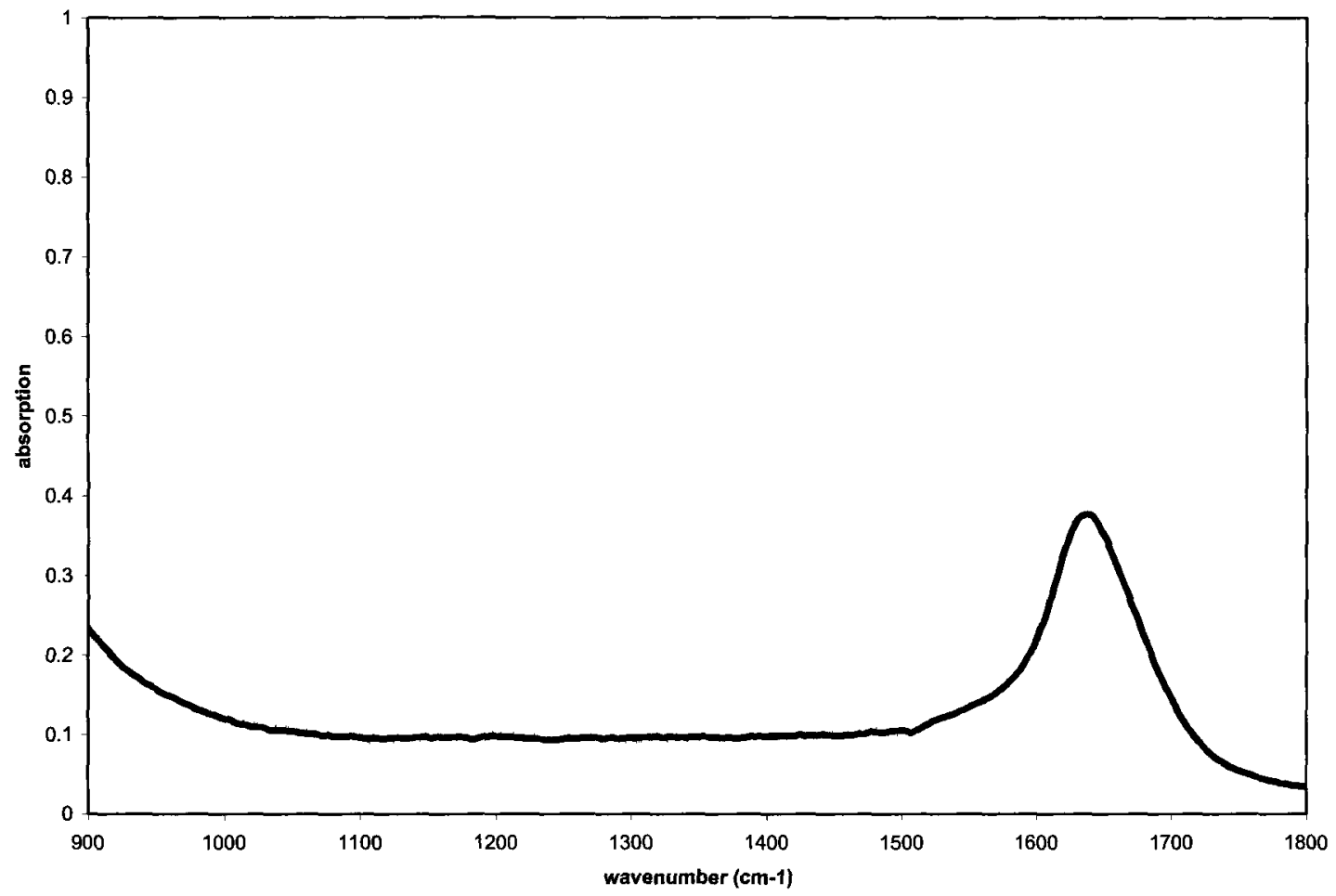

Figure 13, Absorption of pure water using FEWS methodology.

To further investigate the effects of water, measurements of a sample were taken at several time intervals as the sample had undertaken successive drying times in the same manner described above. Figure 14 shows the absorption spectra changes of the sample before and after a complete drying cycle time of no more than 2 minutes. Two important effects can be readily observed. Due to higher water content, the absorption of the radiation by the tissue itself is first decreased causing an overall drop in the spectrum. The drop is also preferentially biased towards the glycogen range around $1000 \mathrm{~cm}^{-1}$. Protein peaks around $1600 \mathrm{~cm}^{-1}$ tend to remain relatively higher due to the absorption of water at those wavelengths as discussed above. Secondly, absorption peaks tend to be washed out by water. Features most affected by this will be the smaller peaks such as the 
important $970 \mathrm{~cm}^{-1}$ peak typically found in malignant samples. In figure 14, the peak appearing around $940 \mathrm{~cm}^{-1}$ in the dry sample was washed out when the sample still had high water content. Peaks in the $1200 \mathrm{~cm}^{-1}$ to $1500 \mathrm{~cm}^{-1}$ range are also diluted in the wet sample and would be difficult to use for assessing absorption shifts.

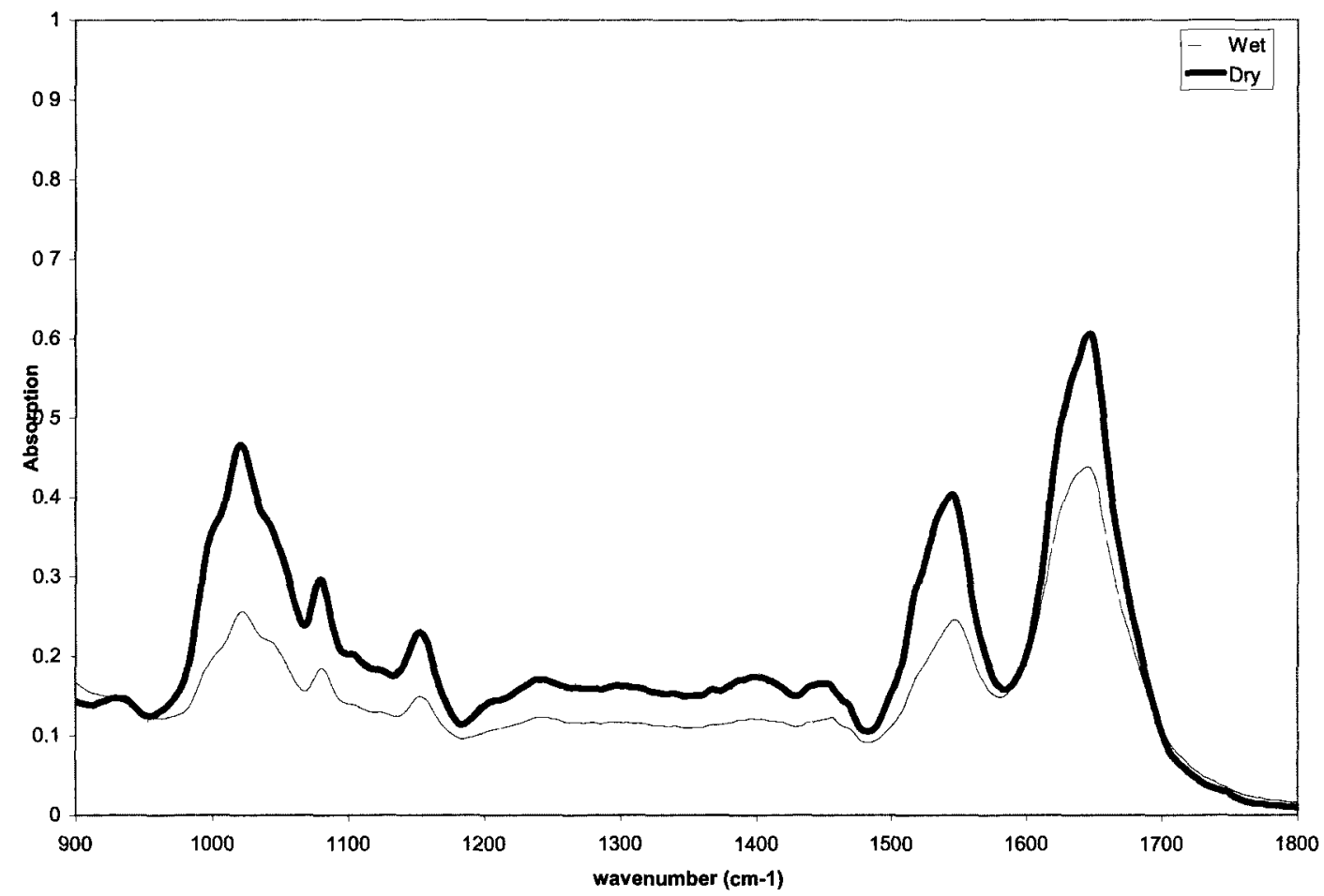

Figure 14. Absorption spectra of a sample when still wet and after drying.

These measurements were acquired specifically to assess the impact of water content within the scope of this study and demonstrate the need for drying the samples prior to measurement. Sharp peaks are needed to optimize the estimate of spectral shifts and ensure that the less intense absorption peaks are also above the detection threshold. In an 
in-vivo environment, it is doubtful any drying process will be used. An assessment of the water content impact in-vivo must be performed separately. 


\section{Sample Probe and Holder Absorption}

The spectrometer heat source spectrum and the transmission levels across the fiber and through the silicon sample holders were measured in order to assess any potential confounding effects. Figure 15 first shows the source spectrum as measured using an open beam (i.e. no apparatus between the exit and entrance apertures of the spectrometer where the sample is normally placed). The spectrometer was continuously purged with dry air from the Balston gas generator to avoid any water moisture interference. As expected, the spectrum shows a blackbody emission curve typical of a heat source.

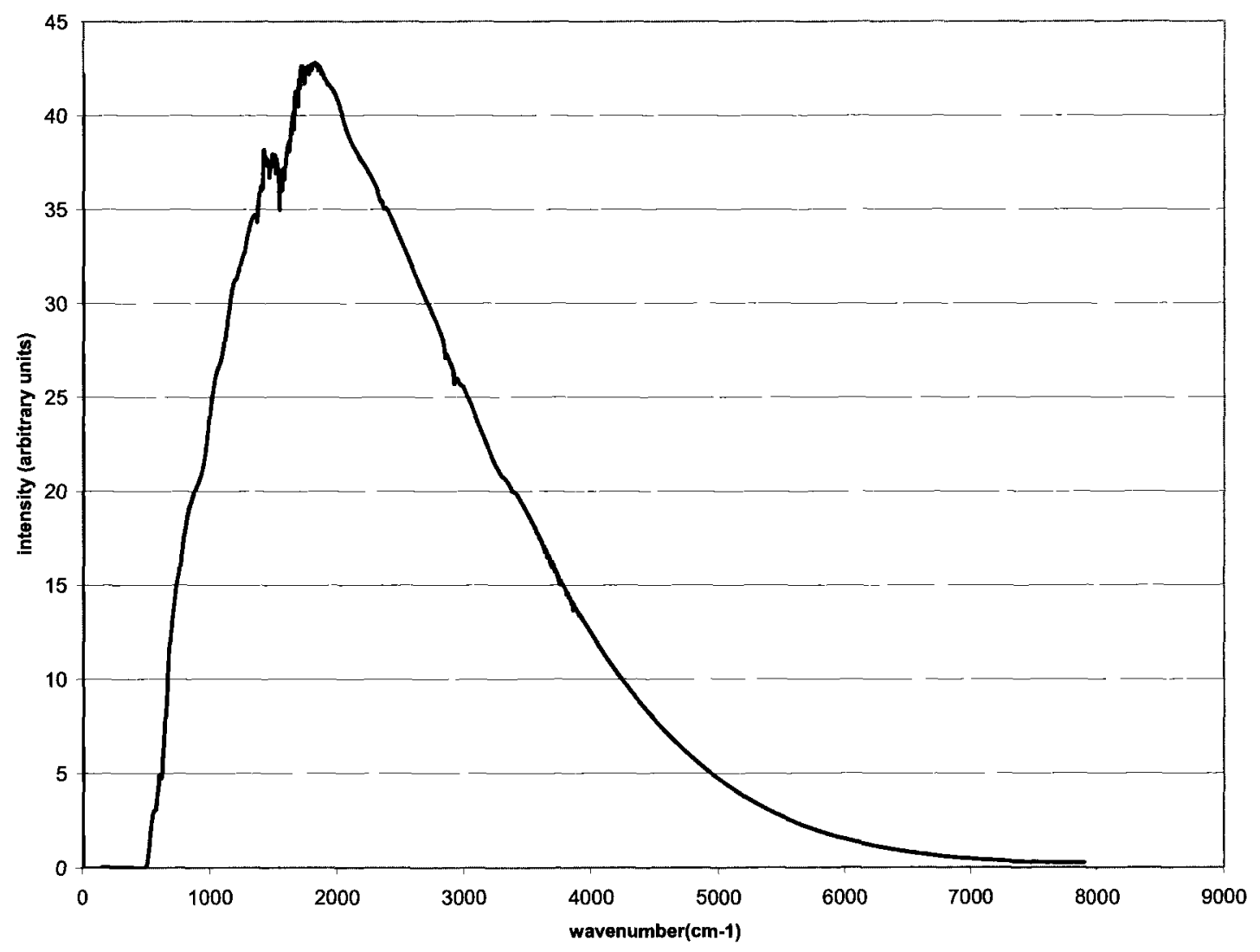

Figure 15. Emission spectrum of the spectrometer heat source. 
Figure 16 shows the absorption spectra of the silver halide fiber and coupler assembly across the range used for the spectral analysis. This absorption spectra is referenced to the open beam spectra and therefore includes the absorption and losses due to the fiber integrated to the optical coupler. Characteristics to be avoided in transmission media used in these studies are those showing very sharp changes and any lack of transmission over some wavelengths. The silver halide fiber curve shows a wide variation of absorption over the range of interest but a continuous one nonetheless. Over the period of twenty minutes, ten spectral readings were acquired of this absorption curve and no variation at any wavelength could be detected. Any possible changes in fiber transmission over the period of this study would also be corrected for by the constant acquisition of reference spectra prior to every sample measurement. 


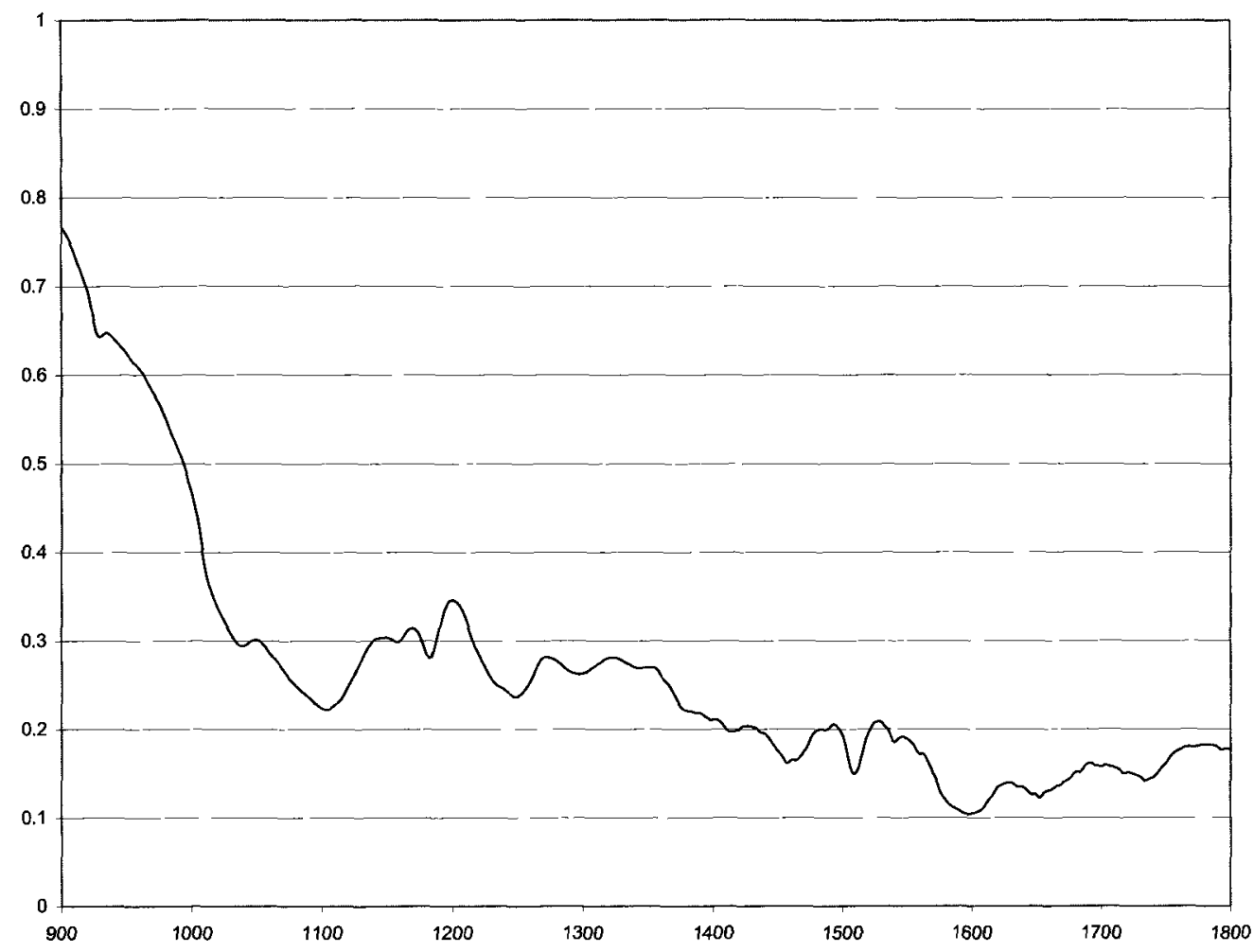

Figure 16. Transmission of silver halide fiber and coupler assembly.

Similarly, figure 17 shows the absorption spectra of the silicon sample holder. Around $1100 \mathrm{~cm}^{-1}$, the silicon sample holder does show an absorption peak but no significant overall decrease. The absorption peak is due to the molecular structure of the silicon wafer on which the sample is placed. It therefore does remain very constant over the lifetime of the slide and its effect on the sample absorption spectra is eliminated through the acquisition of a reference spectrum prior to each sample measurement. The silicon sample holder offers many advantages such as affordability, readiness of use and disposability and was therefore used for all absorption measurements. 


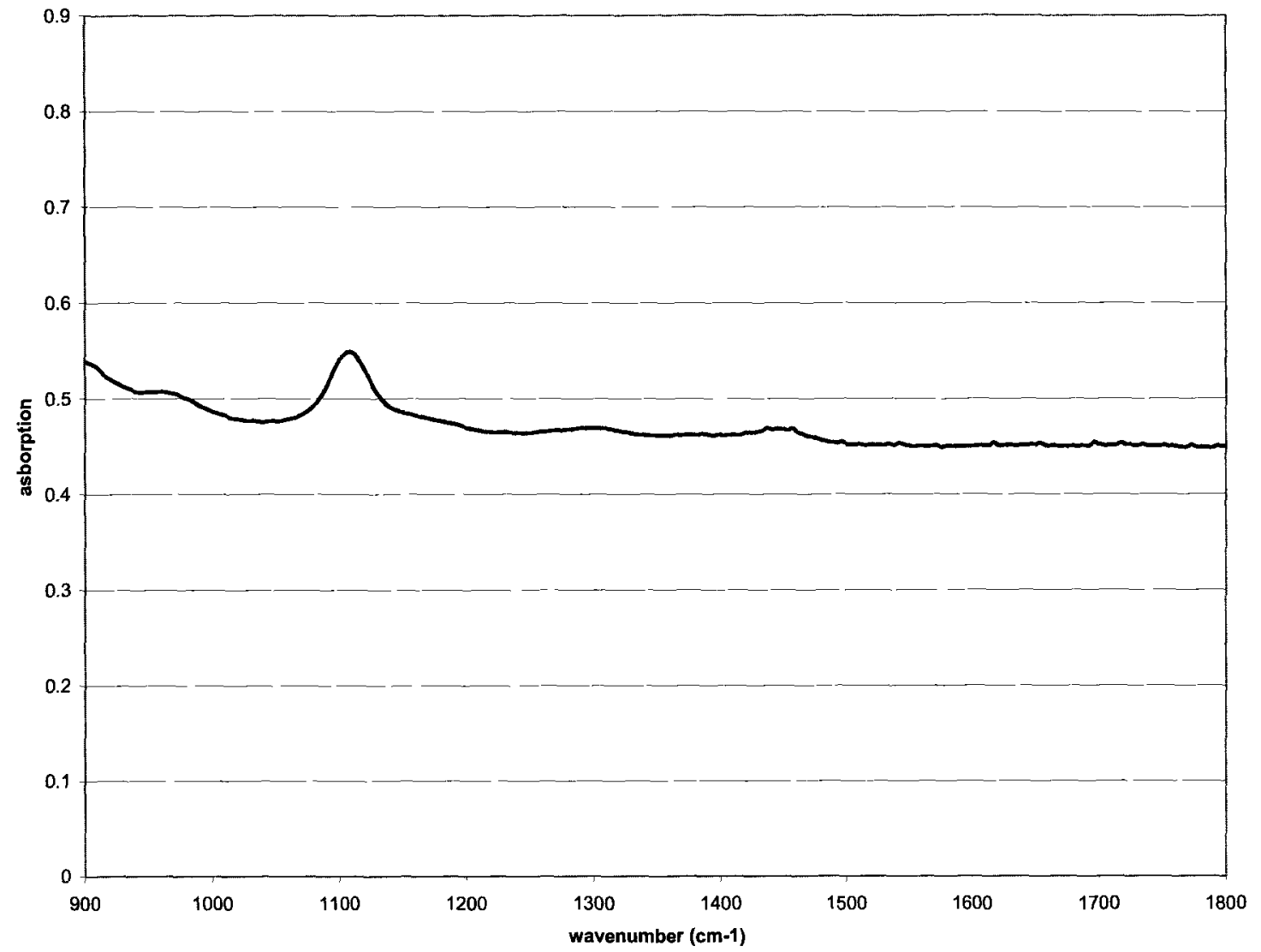

Figure 17. Absorption of the silicon sample holder. 


\section{Normal Diagnosis (sample \#15)}

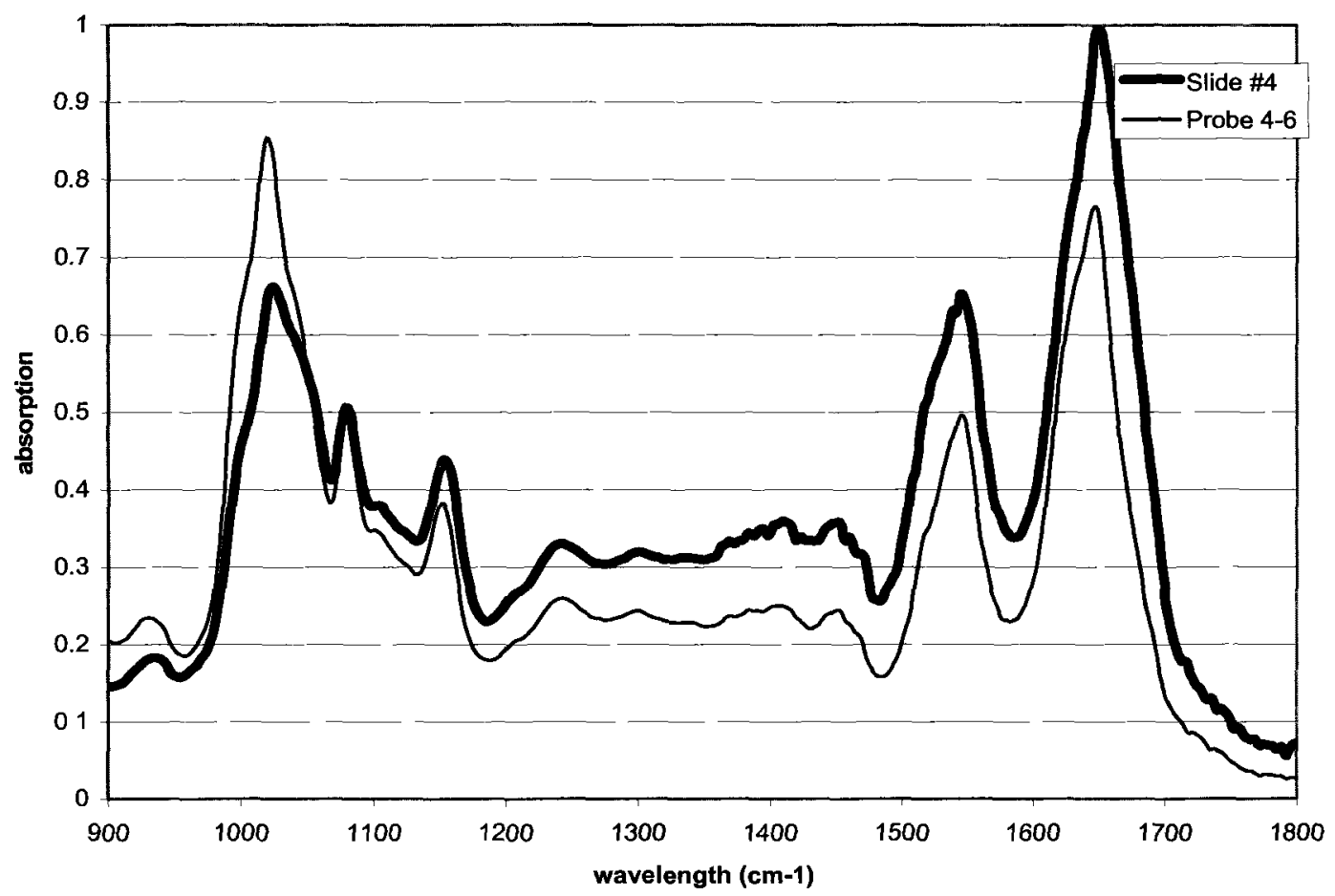

Figure 18. Absorption spectra of a normal tissue sample.

Figure 18 shows the spectral absorption curve of one sample (numbered 15) measured both in the traditional transmission setup (labeled 'slide') and in the FEWS approach (labeled 'probe'). These spectra of healthy cervical tissue are consistent with published literature and show the expected overall shape and relative intensity. A small absorption peak is observed at about $940 \mathrm{~cm}^{-1}$ which has been associated to healthy tissue cells as previously discussed. Strong glycogen bands are present in the $1000-1100 \mathrm{~cm}^{-1}$ region with a peak at 1082 associated with nucleic acids [50]. Collagen absorption peaks are present at 1244 and $1303 \mathrm{~cm}^{-1}$. Strong protein bands, originating largely from DNA, are also present in the $1500-1700 \mathrm{~cm}^{-1}$ region. These bands have typically been reported in 
the literature to remain stronger as the cell undergoes dysplastic transformation or degradation and are therefore useful to use as baseline intensities to derive relative intensity changes in other parts of the spectrum. 


\section{Abnormal Diagnosis (sample \#19)}

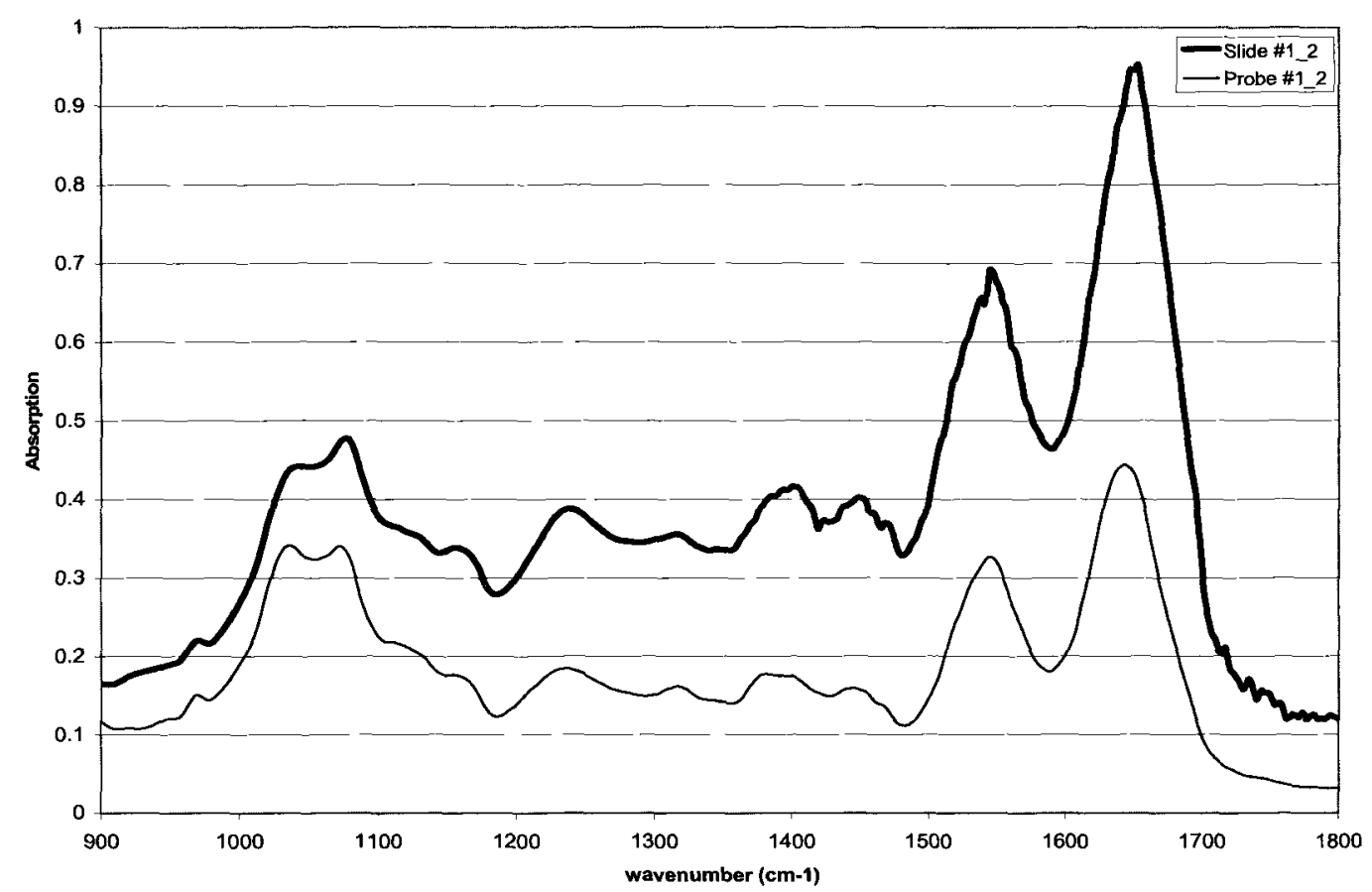

Figure 19. Absorption spectra an abnormal tissue sample.

Figure 19 shows the spectral absorption of an example sample typical of those classified as abnormal (or likely malignant). The spectrum acquired through the fiber probe shows notably less absorption than the absorption measurement made through the transmitting silicon sample holder. The reason for this is related to the sample preparation protocol and does not, in essence, alter the diagnostic value of the data since the assessment is made based on the relative intensities of the bands, the presence or absence of some bands, and the shifting of peaks. The average intensity is therefore not important and is actually more indicative of the quantity of sample used in the preparation and the extent of surface contact made between the probe and the sample. As a consequence, relative intensities can be used to assess the spectral changes as in figure 20 showing both the 
fiber probe absorption spectra of the normal sample \#15 presented earlier and the abnormal sample \#19. In this graph, the spectra were normalized to have a similar1650 $\mathrm{cm}^{-1}$ intensity. This wavelength was selected as it represents a protein absorption peak which remains fairly constant through dysplasic cell transformation as previously discussed. Only the range of interest between 900 and $1350 \mathrm{~cm}^{-1}$ is shown.

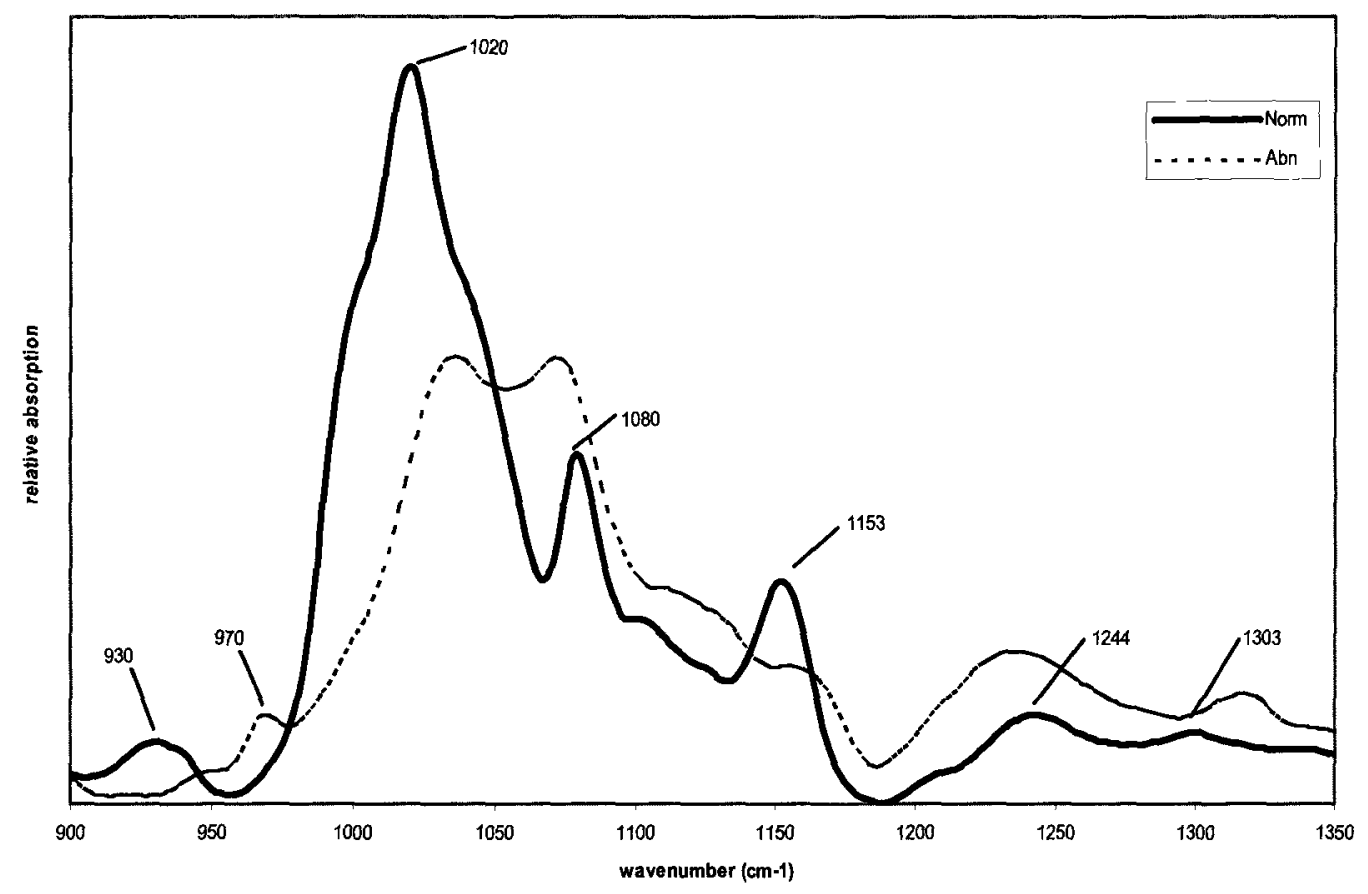

Figure 20. FEWS absorption spectra of a normal and abnormal sample.

The absorption band at $930 \mathrm{~cm}^{-1}$ is absent in the abnormal sample. This is replaced by a peak at $970 \mathrm{~cm}^{-1}$. The $930 \mathrm{~cm}^{-1}$ peak assignment remains unclear in the literature but there has been reference to its origin in the left-handed helix of DNA. The reason for its consistent disappearance in abnormal tissue suggests significant alteration in the DNA but no exact explanation has been reported. The appearance of the $970 \mathrm{~cm}^{-1}$ peak in abnormal tissue is assigned to stretching vibrations of phosphate monoesters. These 
phosphate groups form the backbone of DNA structures and can also originate in protein makeup. The appearance of this band again suggests significant alteration of the DNA in abnormal cells. Next is the significant decrease in absorption between 1000 and 1060 $\mathrm{cm}^{-1}$ region typically indicative of glycogen content. There are a number of reports in the literature as mentioned earlier noting a significant drop in the glycogen content of malignant tissue which would support the consistent change in spectral response observed throughout the samples studied here. This decrease in the overall absorption is also accompanied by a shift in the $1020 \mathrm{~cm}^{-1}$ peak. The $1080 \mathrm{~cm}^{-1}$ is also found to shift as well as increase its relative intensity in the abnormal tissue. This is assigned to phosphate groups in nucleic acids. Other changes include the greatly reduced intensity and shifting of the 1155 band assigned to glycogen and proteins and the relative increase and shifting of the 1244 and $1303 \mathrm{~cm}^{-1}$ bands in the abnormal tissue spectra which are assigned to collagen.

Detailed biochemical explanations of these observed changes are still not well understood. Until they are founded on solid theoretical basis, diagnostic analysis of malignancy will largely be based on empirical findings. It is emphasized that findings in this study are not meant to confirm the classification scheme designed by Wong et al. [50] and used herein as this would require independent histology and is outside the scope of this project. Evidence of the predictive ability of the classification scheme has however been reported elsewhere $[60,77]$. The purpose of this study is to confirm that FEWS provides a mechanism as effective as the traditional FTIR transmission approach used in all previous studies on cervical samples. 


\section{Degraded Diagnosis}

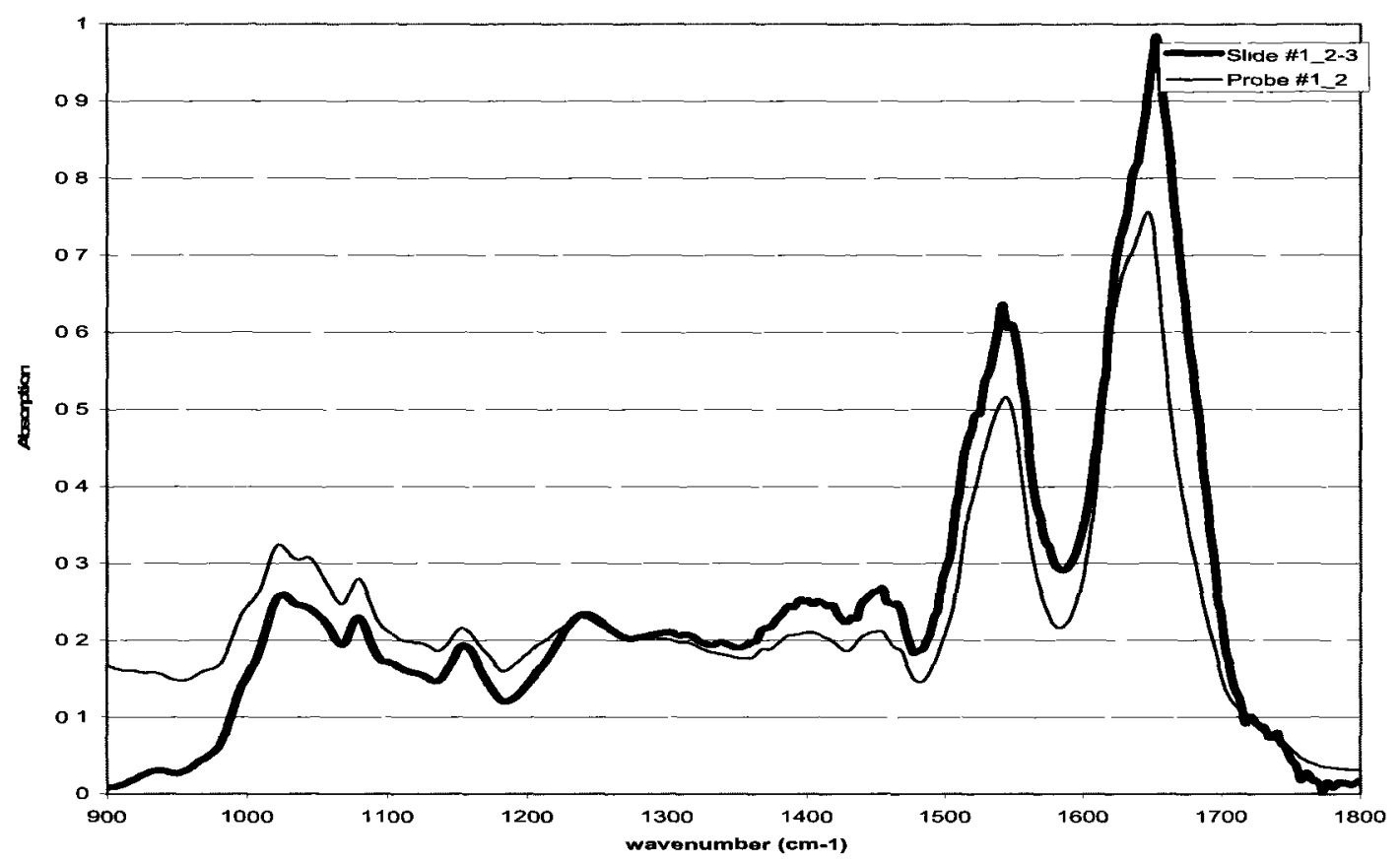

Figure 21. Absorption spectra of degraded tissue.

Some samples such as the one shown in figure 21 were classified as degraded. Whether the samples had degraded while in storage or as a result of poor sample preparation is likely to be a result of an overextended drying time which would have resulted in cellular breakdown. These samples show a marked lack of glycogen absorption in the 1000 to $1100 \mathrm{~cm}^{-1}$ region. Collagen bands in the $1200-1350 \mathrm{~cm}^{-1}$ region also appear to have lost considerable structure. While a weak signal reaching the spectrometer detector would show similar weak absorption bands in that range, it would not show the relatively much more pronounced protein bands in the $1500-1700 \mathrm{~cm}^{-1}$ region which are still very strong in degraded tissue. It is therefore obvious that the sample cellular structure itself has, in these cases, undergone drastic changes. In many aspects, degraded spectra may resemble 
those from abnormal tissue. Similar band shifts as well as a significant drop in glycogen levels are observed in both instances. A most important parameter allowing differentiation between these cases is the relative drop in glycogen levels as compared to the more constant protein absorption bands in the $1500-1700 \mathrm{~cm}^{-1}$ region. Figure 22 compares this degraded sample to the previously discussed abnormal sample 19.

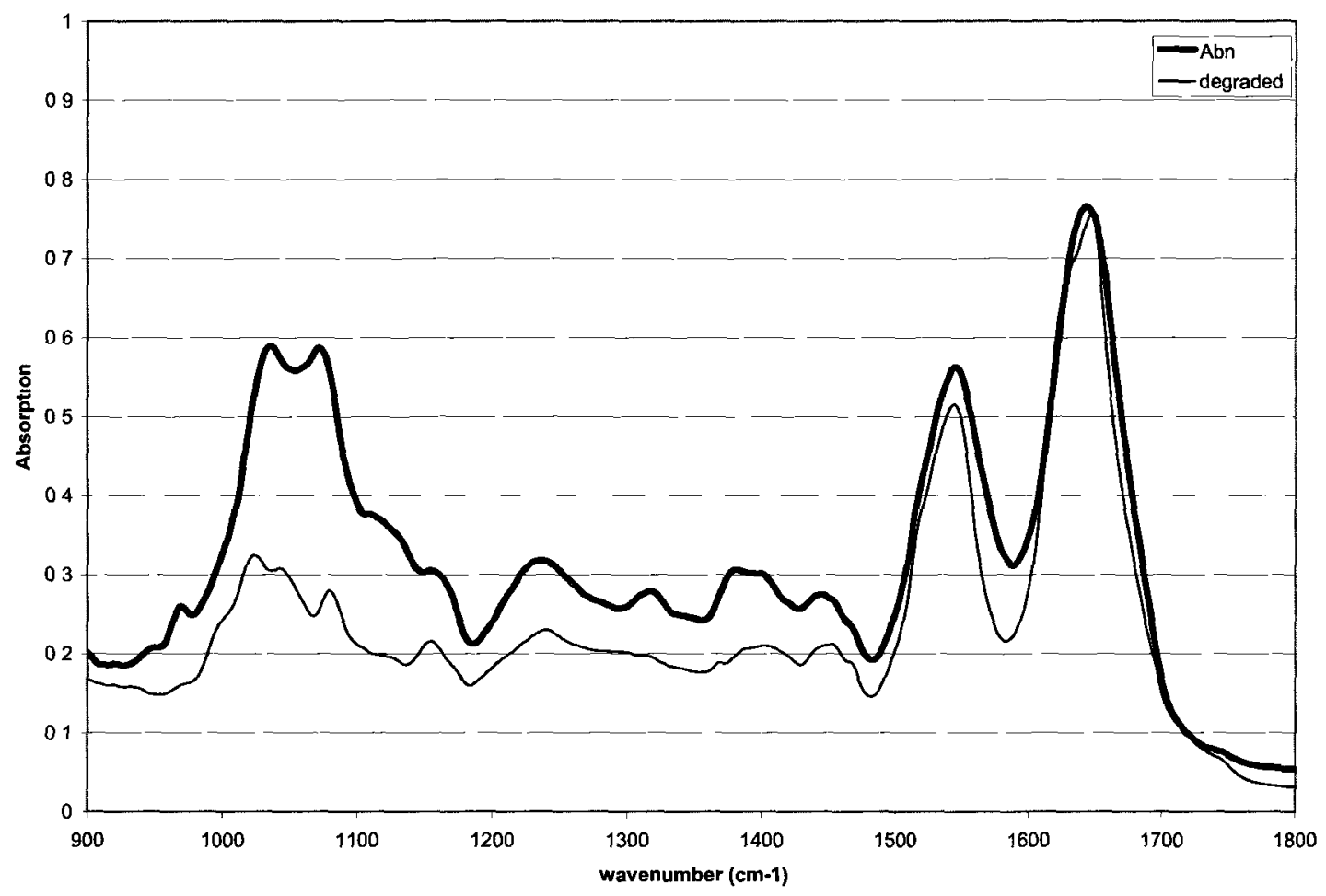

Figure 22. A comparison of a degraded and an abnormal sample.

It is readily seen that although the absorption peak at $1650 \mathrm{~cm}^{-1}$ is similar in both cases, the glycogen bands in the $1000 \mathrm{~cm}^{-1}$ to $1150 \mathrm{~cm}^{-1}$ range are very much altered. Differences also come about between $1200 \mathrm{~cm}^{-1}$ and $1500 \mathrm{~cm}^{-1}$. A preset threshold level can be set below which the band intensity ratio between these ranges can be said to detect tissue degradation. 
It is expected that within the in-vivo environment, this classification group will play a much less important, if any, role as degraded tissue is not likely to be frequently encountered. It is however hypothesized that dead tissue may show similar spectral response. This issue has not been addressed here however and further investigations would be required. 


\section{Unclear Diagnosis}

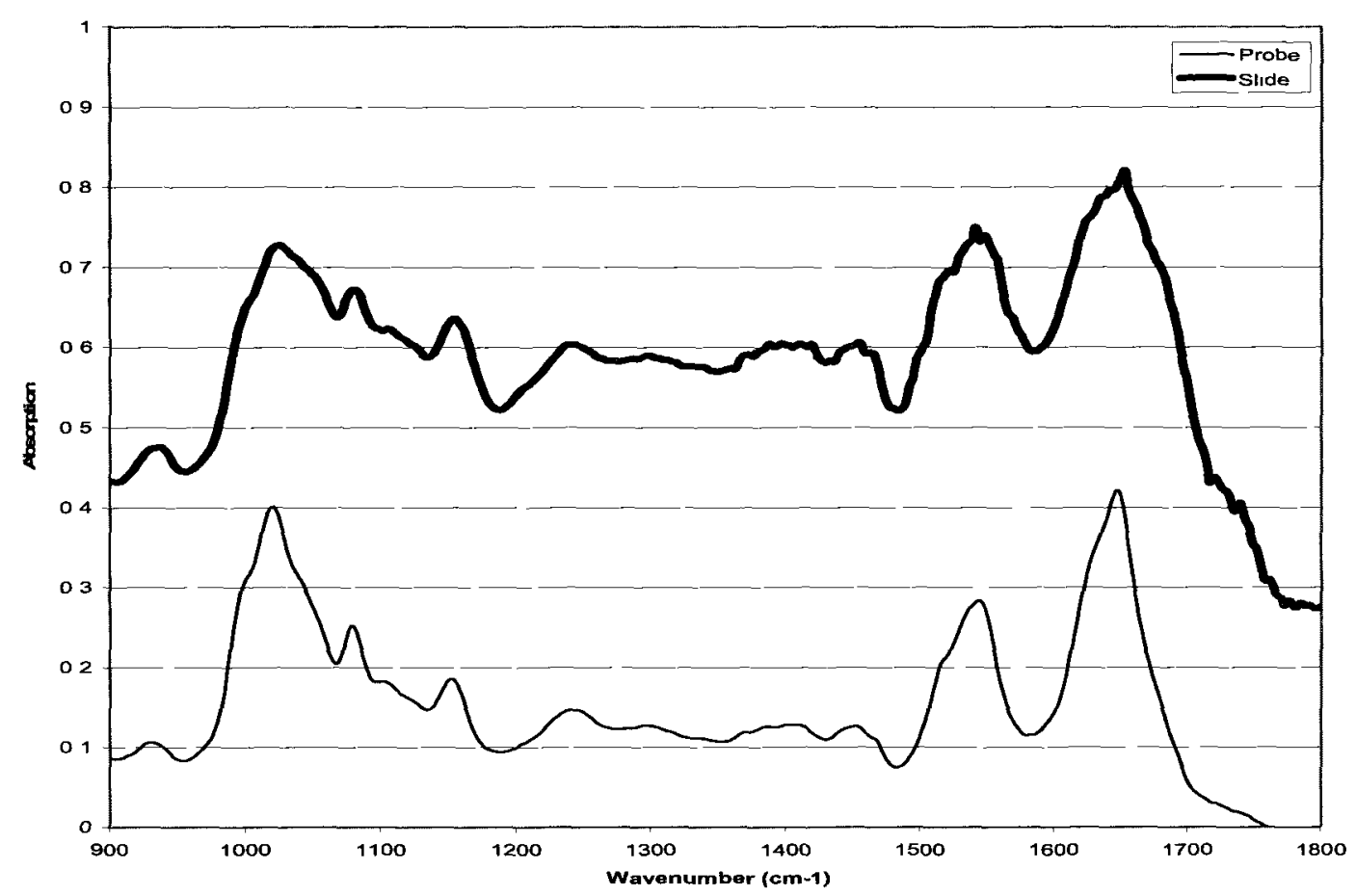

Figure 23. Absorption spectra of a sample showing unclear results.

Of all samples investigated, only one (sample \#9) showed a conflicting diagnosis between the traditional and the FEWS approach. Figure 23 shows the spectra for this sample. The vertical offset between the slide and probe readings are more indicative of sample preparation variances than actual differences in absorption properties and are largely inconsequential in terms of diagnostic value. The absorption peaks and overall behaviour across the spectral range are the factors that carry relevant information and are the same in both readings. The only observed differences are a slightly higher noise level in the slide spectra in the region above $1400 \mathrm{~cm}^{-1}$ and a slightly lower relative intensity in the glycogen bands. Both these can be readily attributed to sample preparation. The 
noise level above $1400 \mathrm{~cm}^{-1}$ is a result of the silicon chip used to fix the sample and has been previously discussed. The slightly lower glycogen levels in the slide reading can be a result of a moderately excessive drying time. This sample was among the ones containing a smaller amount of initial material to work with, and as a result of the smaller amount of tissue on both the probe and slide holder, all absorption peaks were attenuated. It is therefore believed that the combined effects of a smaller amount of tissue and the slight excess in drying time were the direct cause of the differences in spectral readout. Both readings were not so degraded as to be considered invalid but were enough to cause a slight differing diagnostic classification. This sample exemplifies the difficulty and importance of proper sample preparation. 


\section{Conclusion}

The aim of this project was to assess the FEWS approach for cervical tissue malignancy detection and diagnosis in relation to traditional techniques. To this end, 23 cervical tissue samples were prepared and measurements were made on each sample using both the FEWS and traditional methodologies. An automated classification was then performed on both sets of measurements using the diagnostic parameters described in detail above. Comparison of the classification results are used to prove the feasibility of using FEWS as a diagnostic tool in a manner at least as accurate as traditionally possible.

Of the 23 samples examined, 12 provided valid spectra for further diagnosis. Due to the lack of history and experience in this field, sample application methodologies proved faulty in most of the initial trials. Of the latter successful measurements, both methodologies provided similar classification of the tissue samples. Only one had differing diagnosis which, it is argued, is more related to the sample preparation than to the spectral processing part of the analysis. FEWS therefore does, in this regard, provide the same spectral information that can be used to assess the health of the tissue based on the classification parameters defined for malignant transformation. It is again emphasized that the classification scheme is not validated by any means in this study. It has only been used to serve the purpose of providing a common baseline from which to derive a diagnosis from all absorption spectra. 
Some important potential problems must however still be investigated before it can be claimed that the diagnosis of malignant changes can be performed in-vivo. These problems are related not to the FEWS technique as such but to the environment in which the measurements would be performed in an in-vivo setting. Within the in-vivo environment, some complications are eased but others surface. These include:
a) no mixing of the sample layers
b) presence of mucus and other contaminants
c) operational difficulties of acquiring a measurement
d) variances in the spectral response.

The biopsy samples investigated were well mixed prior to measurement thus changing the natural distribution of cells that would be found in-vivo. Whether this has any impact on the spectral response is questionable but the possibility should be addressed. Of more concern is the presence of considerable mucus and other contaminants that may very well affect not only the spectral response in an in-vivo setting but also the depth to which the radiation will reach into the tissue of interest. Wong et al. [59] did report mucus as being a potential confounding factor as previously mentioned. It is proposed that some cleaning technique may resolve this issue but further work would be required to demonstrate this. Operational considerations are also to be considered for an in-vivo application. This technique would undoubtedly be used in conjunction with some fiberbased visualization procedure. Although no major obstacle would be expected here, the operational details of clinical use must be given high importance if this technology is to be seriously considered for regular use especially given the very low tolerance of the clinical medical community to any introduction of new technologies. Finally, and most 
significant, are the potential differences that might exist between biopsy samples and invivo tissue although none are expected given the preservation protocols used. It has generally been found that fresh tissue samples such as those used in this study do preserve their spectral characteristics. Nonetheless, to strengthen any hypothesis made, it is suggested that follow-up work directly address this issue as well.

Given the results of this study, it is safe to say that the outlook for this technology is promising. It has been demonstrated here that FEWS does provide the same spectral information as traditional FTIR spectrometry with the advantage that it opens up in-vivo applications. It is this advantage that must be further developed. An ideal follow-up project would be to repeat these same measurements in a clinical setting even on a small number of patients. Measurements could be made either directly on the tissue or even immediately after the tissue has been excised by biopsy. This would allow the verification of all the above stated complications and would alleviate any concerns of the applicability of FEWS as a standard tool for cervical cancer diagnosis. 


\section{REFERENCES}

1. Walsh, M., German, M, Singh, M., Pollock, H., Hammiche, A., Kyrgiou, M., Stringfellow, H., Paraskevaidis, E., Martin-Hirsch., P., Martin, F., IR microspectroscopy: potential applications in cervical cancer screening, Cancer Letters, 246, 2007, 1-11

2. Modern Spectroscopy, $4^{\text {th }}$ ed., edited by J. Michael Hollas, Wiley \& Sons, 2004.

3. Bindig, U., Muller, G., Fiber-optic laser-assisted infrared tumour diagnostics (FLAIR), J. Phys. D: App. Phys., 38, 2005, 2716-2731.

4. Afanasyeva, N., Kolyakov, S., Bruch, R., Gummuluri, S., Biomedical, environmental and industrial application of fiberoptical infrared spectroscopy, Proceedings of SPIE Vol. 4129, 2000, 272-283.

5. Wang, G.Z., Murphy, K.A., Claus, R.O., 1995. Effect of external index of refraction on multimode fiber couplers. Appl. Opt. 34 (36), 8289-8293.

6. Optics, E.Hecht, Pearson Education, p.122, 2002.

7. Bindig, U., Gersonde, I., Meinke, M., Becker, Y., Mueller, G., IR fiber optic sensing on biological tissue, Proceedings of the SPIE - The International Society for Optical Engineering, v 5068, n 1, 2003, 134-41

8. Bindig, U., Frank, F., Gersonde, I., Meinke, M., Zelianeos, K., Katzir, A., Muller, G., Fiber-optic and microscopic infrared biodiagnostics, Laser Physics, v 13, n 1, Jan. 2003, 96-105

9. Movasaghi, Z., Rehman, S., Rehman, I. Ur, Fourier transform infrared (FTIR) spectroscopy of biological tissues, App. Spec. Rev., 2008, vol. 43, 134-179.

10. Artyushenko, V., Wojciechowski, C., Ingram, J., Kononenko, V., Lobachev, V., Sakharova, T., Ludczak, J., Grzebieniak, A., Wojciechowski, Z., Specialty fibers 
for broad spectra of wavelength and power, Proceedings of the SPIE - The International Society for Optical Engineering, v 5951, n 1, 2005, 1-8

11. Artjouchenko, V., Lobachev, V.A., Nikitin, M., Sakharova, T., Sakharov, V., Wojciechowski, C., PIR fiber sensing in 4- to 18-\&mu,m range for flexible IR imaging and process IR spectroscopy, Proceedings of the SPIE - The International Society for Optical Engineering, v 5502, n 1, 2004, 295-9

12. Harrington, J., Infrared Fibers, Handbook of Optics, 2000, Chapter 14.

13. Harrington, J., A review of IR transmitting, hollow waveguides, Fiber and Integrated Optics, vol. 19, 2000, 211-227.

14. Butvina, L.N., Dianov, E.M., Lichkova, N.V., Zavgorodnev, V.N., Kuepper, L., Crystalline silver halide fibers with optical losses lower than $50 \mathrm{~dB} / \mathrm{km}$ in broad IR region, Proceedings of the SPIE - The International Society for Optical Engineering, v 3849, 1999, 181-8

15. Takebe, H., Kitagawa, R., Hewak, D.W., Non-toxic sulphide glasses and thin films for optical Applications., Journal of the Ceramic Society of Japan, vol. 113, n $1,2005,37-43$

16. Sanghera, J.S., Shaw, L.B., Busses, L.E., Nguyen, V.Q., Pureza, P.C., Cole, B.C., Harrison, B.B., Aggarwal, I.D., Mossadegh, R., Development and infrared applications of chalcogenide glass optical fibers, Fiber and Integrated Optics, vol. $19,2000,251-274$.

17. Zhang, X.H., Calvez, L., Seznec, V., Ma, H.L., Danto, S., Houizot, P., BoussardPledel, C., Lucas, J., Infrared transmitting glasses and glass-ceramics, Journal of Non-Crystalline Solids, v 352, n 23-25, 15 July 2006, 2411-15

18. Bureau, B., Xiang Hua Zhang, Smektala, F., Adam, J.-L., Troles, J., Hong-Li Ma, Boussard-Pledel, C., Lucas, J., Lucas, P., Le Coq, D., Riley, M.R., Simmons, J.H., Recent advances in chalcogenide glasses, Journal of Non-Crystalline Solids, $v$ $345-346,15$ Oct. $2004,276-83$ 
19. Sundaram, S.K., Johnson, B.R., Schweiger, M.J., Martinez, J.E., Riley, B.J., Saraf, L.V., Anheier N.C., Allen, P.J., Chalcogenide glasses and structures for quantum sensing, Quantum Sensing and Nanophotonic Devices, Proceedings of the SPIE, vol. 5359, 2004, 234-244

20. Shephard, J.D., Kangley, R.I., Hand, R.J., Furniss, D., Miller, C.A., Seddon, A.B., Properties of Ga-La-Na sulphide glasses, Journal of Non-Crystalline Solids, $\mathrm{v}$ 332, n 1-3, 15 Dec. 2003, 271-8

21. Poulain, M. , Fluoride glass fibers: applications and prospects, Proceedings of the SPIE - The International Society for Optical Engineering, v 3416, 1998, 2-12

22. Saad, M., Tasse, J.S., Fluoride glasses draw fiber into the mid-infrared, Laser Focus World, v 43, n 5, 2007, 105-8

23. Miyagi, M., Kawakami, S., Design theory of dielectric-coated circular metallic waveguide for infrared transmission, Journal of Lightwave Technology, LT-2, n. $2,1984,116-126$.

24. Dahan, R., Dror, J, Croitoru, N., Characterization of chemically formed silver iodide layers for hollow infrared guides, Material Research Bulletin, vol. 27, 1992, 761-766.

25. Kasahara, R., Matsuura, Y., Katagiri, T., Miyagi, M., Transmission properties of infrared hollow fibers produced by drawing a glass-tube perform, Optical Engineering, v 46, n 2, Feb. 2007, 25001-1-5

26. Yi Wei Shi, Ito, K., Matsuura, Y., Miyagi, M., Multiwavelength laser light transmission of hollow optical fiber from the visible to the mid-infrared, Optics Letters, v 30, n 21, 1 Nov. 2005, 2867-9

27. Shalem, S., German, A., Barkay, N., Moser, F., Katzir, A., Mechanical and optical properties of silver-halide infrared transmitting fibers, Fiber and Integrated Optics, v 16, n 1, 1997, 27-54

28. German, A., Barkay, N., Katzir, A., High-cycle fatigue of silver halide infrared fibers, Applied Optics, v 33, n 13, 1 May 1994, 2734-6 
29. Barkay, N., Katzir, A., Transmission of infrared laser radiation through silverhalide optical fibers during repeated plastic deformation, Journal of Lightwave Technology, v 11, n 12, Dec. 1993, 1889-94

30. Barkay, N., Katzir, A., Elasticity of mixed silver-halide polycrystalline optical fibers , Journal of Applied Physics, v 74, n 4, 15 Aug. 1993, 2980-2

31. Nagli, L., Bunimovich, D., Shmilevich, A., Kristianpoller, N., Katzir, A., Optical properties of mixed silver halide crystals and fibers, Journal of Applied Physics, $v$ 74, n 9, 1 Nov. 1993, 5737-41

32. Artjushenko, V.G., Lerman, A.A., Litvinenko, E.G., Nabatov, A.O., Konov, V.I., Kuznetsov, R.I., Mechanisms of optical losses in polycrystalline fibers, Proceedings of the SPIE - The International Society for Optical Engineering, $v$ $1591,1992,83-9$

33. Barkay, N., Katzir, A., Mechanical resistance of silver halide infrared fibers, Proceedings of the SPIE - The International Society for Optical Engineering, $v$ $1591,1992,50-9$

34. Dahan, R., Dror, J, Croitoru, N., Characterization of chemically formed silver iodide layers for hollow infrared guides, Material Research Bulletin, vol. 27, 1992, 761-766.

35. Barkay, N., Levite, A., Moser, F., Kowal, DF., Katzir, A., Optical properties of mixed silver halide crystals and polycrystalline optical fibers, Proceedings of the SPIE - The International Society for Optical Engineering, v 1048, 1989, 9-16

36. Kirsh, Y., Schnitzer, I., Townsend, P., Radioluminescence of silver halide optical fibers, Journal of the Optical Society of America B (Optical Physics), v 6, n 2, Feb. 1989, 146-50

37. Sa'ar, A., Barkay, N., Moser, F., Schnitzer, I., Levite, A., Katzir, A., Optical and mechanical properties of silver halide fibers, Proceedings of the SPIE - The International Society for Optical Engineering, v 843, 1988, 98-104 
38. Sa'ar, A., Moser, F., Saban, S., Weiss, D., Katzir, A., Optical properties of silver halide infrared transmitting fibers, Proceedings of the SPIE - The International Society for Optical Engineering, v 618, 1986, 81-4

39. Sa'ar, A., Katzir, A., Intrinsic losses in mixed silver halide fibers, Proceedings of the SPIE - The International Society for Optical Engineering, v 1048, 1989, 24 31

40. Sa'ar, A., Moser, F., Akselrod, S., Katzir, A, Infrared optical properties of polycrystalline silver halide fibers, Applied Physics Letters, v 49, n 6, 11 Aug. $1986,305-7$

41. Strong, L.H., Masters, J.I., Optical and material properties of extruded silver halide fibers, Proceedings of the SPIE - The International Society for Optical Engineering, v 618, 1986, 72-80

42. Takashi, K., Yoshida, N., Yamauchi, K., Silver halide infrared fiber, Sumitomo Electric Technical Review, n 26, Jan. 1987, 102-9

43. Saito, M., Nakajima, K., Shishido, M., Polymer coating on infrared silver halide fiber for photodarkening protection, Journal of Lightwave Technology, v 20, $n$, March 2002, 441-7

44. Dekel, B.-Z., Katzir, A., Graded-index silver chlorobromide fibers for the midinfrared, Applied Optics, v 44, n 16, 1 June 2005, 3343-8

45. Rave, E., Sade, S., Millo, A., Katzir, A., Few modes in infrared photonic crystal fibers, Journal of Applied Physics, v 97, n 3, 1 Feb. 2005, 33103-1-6

46. Rave, E., Ephrat, P., Katzir, A., AgClBr photonic crystal fibers for the middle infrared, Proceedings of the SPIE - The International Society for Optical Engineering, v 5360, n 1, 9 July 2004, 267-74

47. Millo, A., Naeh, I., Katzir, A., Single-mode segmented cladding fibers for the middle infrared, Journal of Lightwave Technology, v 25, n 8, 2007, 2115-21. 
48. Millo, A. Naeh, I., Lavi, Y., Katzir, A., Silver-halide segmented cladding fibers for the middle infrared, Applied Physics Letters, v 88, n 25, 19 June 2006, 251101-1-3

49. Infrared Spectroscopy of Biomolecules, edited by Henry Mantsch and Dennis Chapman, Wiley-Liss, 1996.

50. Wong, P., Wong, R., Caputo, T., Godwin, T., Rigas, B., Infrared spectroscopy of exfoliated human cervical cells: Evidence of extensive structural changes during carcinogenesis, Proc. Natl Acad. Sci. USA, vol. 88, 1991, pp. 10988-10992.

51. Wong, P.T.T., Lacelle, S., Fung Kee Fung, M., Senterman, M., Mikhael, N., Characterisation of Exfoliated Cells and Tissues from Human Endocervix and Ectocervix by FTIR and ATR/FTIR Spectroscopy, Biospec., vol. 1, 1995, 357364.

52. Fung Kee Fung, M., Senterman, M., Mikhael, N., Lacelle, S., Wong, P.T.T., Pressure-tuning Fourier transform infrared spectroscopic study of carcinogenesis in human endometrium, Biospec., vol. 2, 1996, 155-165.

53. Wood, B., Quinn, M.A., Burden, F.R., McNaughton, D., An investigation into FTIR spectroscopy as a biodiagnostic tool for cervical cancer, Biospectroscopy, vol. 2. 1996, 143-153.

54. Cohenford, M., Rigas, B., Cytologically normal cells from neoplastic cervical samples display extensive structural abnormalities on IR spectroscopy: implications for tumor biology, Proc. Natl. Acad. Sci. USA, vol. 95, 1998, $15327-$ 15332.

55. Cohenford, M., Godwin, T.A., Cahn, F., Bhandare, P., Caputo, T., Rigas, B., Infared spectroscopy of normal and abnormal cervical smears: evaluation by principal component analysis, Gyn. Onc., vol. 66, 1997, 59-65.

56. Chiriboga, L., Xie, P., Yee, H., Vigorita, V., Zarou, D., Zakim, D., Diem, M., Infrared spectroscopy of human tissue. I. Differentiation and maturation of epithelial cells in the human cervix, Biospectroscopy, vol. 4, 1998, 47-53. 
57. Chiriboga, L., Xie, P., Yee, H., Vigorita, V., Zarou, D., Zakim, D., Diem, M., Infrared spectroscopy of human tissue. II. A comparative study of spectra of biopsies of cervical squamous epithelium and of exfoliated cervical cells, Biospectroscopy, vol. 4, 1998, 55-59.

58. Wood, B.R., Quinn, M.A., Tait, B., Ashdown, M., Hislop, T., Romeo, M., McNaughton, D., FTIR microspectroscopic study fo cell types and potential confounding variables in screening for cervical malignancies, Biospec., vol. 4, 1998, 75-91.

59. Wong, P.T.T., Senterman, M.K., Jackli, P., Wong, R., Salib, S., et al. Detailed account of confounding factors in interpretation of FTIR spectra of exfoliated cervical cells, Biopolymers, vol. 67, 2002, 376-386.

60. Sindhuphak, R., Issaravanich, S., Udomprasertgul, V., Srisookho, P., Warakamin, S., Sindhuphak, S., Boonbundarlchai, R., Dusitsin, N., A new approach for the detection of cervical cancer in Thai women, Gynecologic Oncology, 90, 2003, 10 14.

61. Wood, B.R., Chiriboga, L., Yee, H., Quinn, M.A., McNaughton, D., Diem, M., Fourier transform infrared (FTIR) spectral mapping of the cervical transformation zone, and dysplastic squamous epithelium, Gyn. Onc., vol. 93, 2004, 59-68.

62. Mordechai, S., Sahu, R. K., Hammody, Z., Mark, S., Kantarovich, K., Guterman, $\mathrm{H}$., et al., Possible common biomarkers from FTIR microspectroscopy of cervical cancer and melanoma, J. of Microscopy, Vol. 215, 2004, 86-91.

63. Mark, S., Sahu, R. K., Kantarovich, K., Podshyvalov, A., Guterman, H., Goldstein, J., et al., Fourier transform infrared microspectroscopy as a quantitative diagnostic tool for assignment of premalignancy grading in cervical neoplasia, J. Biomed. Opt., vol. 9, 2004, 558-567.

64. Bogomolny, E., Huleihel, M., Suproun, Y., Sahu R. K., Mordechai, S., Early spectral changes of cellular malignant transformation using Fourier transform infrared microspectroscopy, J. Biomed. Opt., vol.12, 2007, 024003. 
65. Faolain, E.O., Hunter, M.B., Byrne, J.M., Kelehan, P., McKamara, M., Byrne, H., Lyng, F. M., A study examining the effects of tissue processing on human tissue sections using vibrational spectroscopy, Vib. Spec., vol. 38, 2005, 121-127.

66. Pleshko, N.L., Boskey, A.L., Mendelsohn, R., An FT-IR microscopic investigation of the effects of tissue preservation on bone, Calcif. Tissue Int., vol. $51,1992,72-77$.

67. Heise, H.M., Kupper, L., Pittermann, W., Stucker, M., Epidermal in vivo an in vitro studies by attenuated total reflection mid-infrared spectroscopy using flexible silver halide fiber-probes, J. Mol. Struc., vol. 651-653, 2003, 127-132.

68. Raichlin, Y., Goldberg, I., Brenner, S., Shulzinger, E., Katzir, A., Infrared fiberoptic evanescent wave spectroscopy for the study of diffusion in the human skin, Proceedings of SPIE, vol. 4614, 2002, 101-108.

69. Eikje, N. S., Ozaki, Y., Aizawa, K., Arase, S., Fiber optic near-infrared Raman spectroscopy for clinical noninvasive determination of water content in diseased skin and assessment of cutaneous edema, J. of Biomed. Opt., vol. 10, 2005, 014013.

70. Bindig, U., Meinke, M., Gersonde, I., Spector, O., Vasserman, I., Katzir, A., Muller, G., IR-biosensor: flat silver halide fiber for bio-medical sensing?, Sensors and Actuators B (Chemical), v B74, n 1-3, 15 April 2001, 37-46

71. Brooks, A.L., Afanasyeva, N.I., Makhine, V., Bruch, R., Kolyakov, S.F., Artjushenko, S., Butvina, L.N., New method for investigations of normal human skin surfaces in vivo using fiber-optic evanescent wave fourier transform infrared spectroscopy (FEW-FTIR), Surf. Interface Anal., vol. 27, 1999, 221-229.

72. Afanasyeva, N.I., Kolyakov, S.F., Butvina, L.N., Remote skin tissue diagnostics in vivo by fiber optic evanescent infrared (FEW-FTIR) spectroscopy, SPIE, vol. 3257, 1998, 260-266.

73. Brooks, A.L., Bruch, R., Afanasyeva, N.I., Kolyakov, S.F., Butvina, L.N., Ma L., Investigations of normal skin tissue using fiberoptic FTIR spectroscopy, SPIE, vol. 3195, 1998, 323-333. 
74. Wong, P.T.T., Goldstein, S., Grekin, R., Godwin, T., Pivik, C., Rigas, B., Distinct infrared spectroscopic patterns of human basal cell carcinoma of the skin, Cancer Research, vol. 53, 1993, 762-765.

75. Mackanos, M. A., Hargrove, J., Wolters, R. Du, C. B., Friedland, S., Soetikno, R. M., et al., Use of an endoscope-compatible probe to detect colonic dysplasia with Fourier transform infrared spectroscopy, J. of Biomed. Opt., vol. 14, 2009, 044006.

76. Bindig, U., Meinke, M., Gersonde, I.H., Spector, O., Katzir, A., Mueller, G.J., IR spectroscopy: new results due to fiber optic sensing in view of biomedical application, Proceedings of the SPIE - The International Society for Optical Engineering, v 4129, 2000, 249-58

77. Maziak, D., Do, M., Shamji, F.M., Sundaresan, S.R., Perkins, G., Wong, P.T.T., Fourier-transform infrared spectroscopic study of characteristic molecular structure in cancer cells of esophagus: An exploratory study, Cancer Detection and Prevention, vol. 31, 2007, 244-253.

78. Dr. Patrick Wong, personal communication, August 2010. 